Florida International University FIU Digital Commons

$11-9-2012$

\title{
Personality and Performance: Assessing the Mediating Role of Mental Model Formation in the Personality-Performance Relationship
}

Eric Cartaya

Florida International University, cartayae@fiu.edu

DOI: $10.25148 /$ etd.FI12120517

Follow this and additional works at: https://digitalcommons.fiu.edu/etd

\section{Recommended Citation}

Cartaya, Eric, "Personality and Performance: Assessing the Mediating Role of Mental Model Formation in the PersonalityPerformance Relationship" (2012). FIU Electronic Theses and Dissertations. 790.

https://digitalcommons.fiu.edu/etd/790 


\section{FLORIDA INTERNATIONAL UNIVERSITY}

Miami, Florida

PERSONALITY AND PERFORMANCE:

ASSESSING THE MEDIATING ROLE OF MENTAL MODEL FORMATION IN THE PERSONALITY-PERFORMANCE RELATIONSHIP

A dissertation in partial fulfillment of the

requirements for the degree of

DOCTOR OF PHILOSOPHY

in

BUSINESS ADMINISTRATION

by

Eric Cartaya

2012 
To: $\quad$ Dean David R. Klock

College of Business Administration

This dissertation, written by Eric Cartaya, and entitled Personality and Performance:

Assessing the Mediating Role of Mental Model Formation in the PersonalityPerformance Relationship, having been approved in respect to style and intellectual content, is referred to you for judgment.

We have read this dissertation and recommend that it be approved.

Sungu Armagan

Nancy Borkowski

Nathan Hiller

Galen Kroeck, Major Professor

Date of Defense: November 9, 2012

The dissertation of Eric Cartaya is approved.

Dean David R. Klock

College of Business Administration

Dean Lakshmi N. Reddi

University Graduate School

Florida International University, 2012 


\begin{abstract}
OF THE DISSERTATION
PERSONALITY AND PERFORMANCE: ASSESSING THE MEDIATING ROLE OF MENTAL MODEL FORMATION IN THE PERSONALITY-PERFORMANCE
\end{abstract}

RELATIONSHIP

\author{
By \\ Eric Cartaya \\ Florida International University, 2012 \\ Miami, Florida \\ Professor Galen Kroeck, Major Professor
}

Personality has long been linked to performance. Evolutions in this relationship have brought forward new questions regarding the true nature of how personality impacts performance. Both direct and indirect relationships have been proven significant. This study further investigated potential indirect relationships by including a mediating variable, mental model formation, in the personality-performance relationship. Undergraduate students were assessed in a 6-week period, Time 1 - Time 2 experiment. Conceptualizations of personality included measures of the Big 5 model and Selfefficacy, with performance measured by content quiz and overall course scores. Findings showed that the Big 5 personality traits, extraversion and agreeableness, positively and significantly impacted commonality with the instructor's mental model. However, commonality with the instructor's mental model did not impact performance. In comparison, commonality with an expert mental model positively and significantly impacted performance for both the content quiz and overall course score. Furthermore, similarity with an expert mental model positively and significantly impacted overall 
course performance. Hypothesized full mediation of mental model formation for the personality-performance relationship was not supported due to a lack of direct effect relationships required for mediation. However, a revised conceptualization of results emerged. Findings from the current study point to the novel and unique role mental models play in the personality-performance relationship. While personality traits do impact mental model formation, accuracy in the mental models formed is critical to performance. 


\section{TABLE OF CONTENTS}

CHAPTER

PAGE

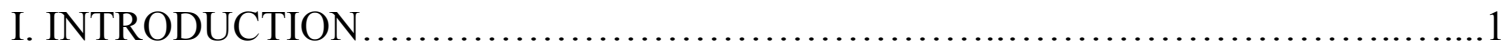

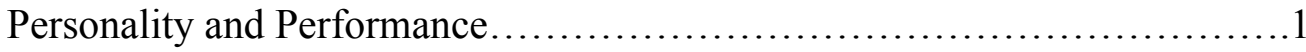

Indirect Approaches to the Personality-Performance Relationship..............2

Validity in the Personality-Performance Relationship......................... 3

Personality Conceptualized through the Big 5 Model..........................4

General Self-Efficacy and Performance.................................6

Mental Models.......................................................

The Big 5, GSE and Mental Models...................................... 7

Mental Models and Performance......................................... 8

Summary of Research Question..........................................11

II. LITERATURE REVIEW AND HYPOTHESES..................................12

Hypothesized Model............................................... 12

Relating Disposition and Performance...................................12

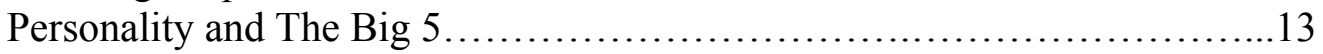

The Big 5 and Performance............................................ 15

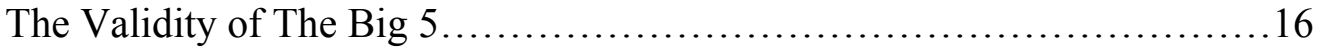

Mediation for the Personality-Performance Relationship...................19

The Big 5 and Mental Models..........................................20

Hypothesized Relationships between the Big 5, Mental Models

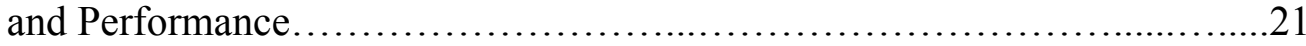

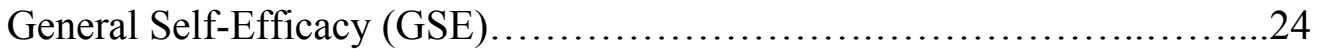

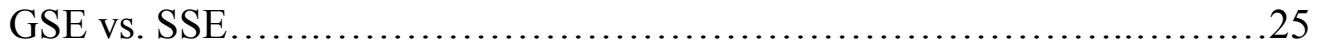

General Self-Efficacy and Performance................................25

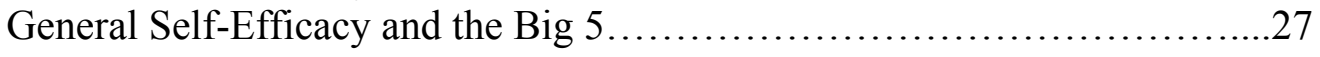

Hypothesized Relationships between GSE, Mental Models and

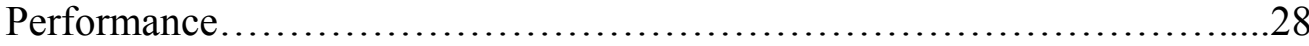

Mental Models............................................................

Mental Models and Knowledge Structures..................................31

Hypothesized Relationships between Mental Models and

Performance............................................................

Summary of Hypotheses..............................................

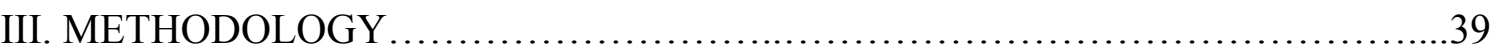

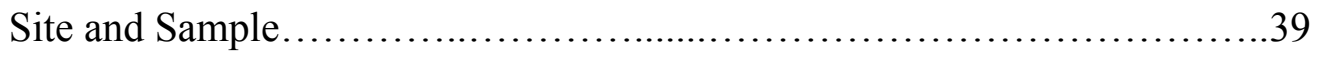

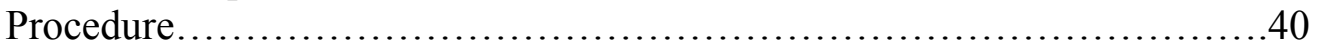

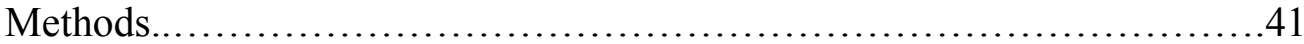

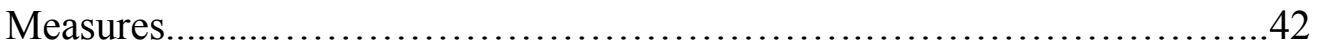

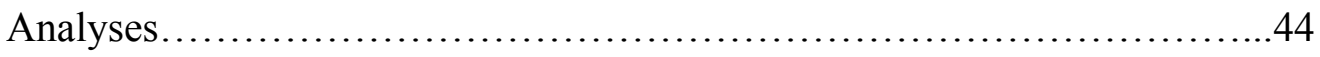


IV. RESULTS ..........................................................49

Test of Hypotheses...............................................5

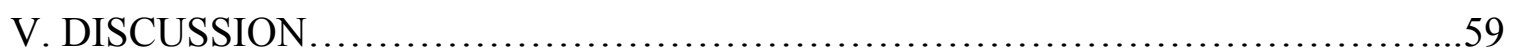

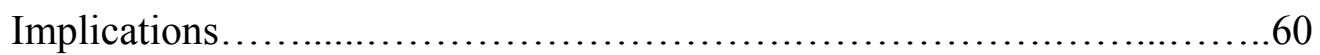

Limitations and Future Research.....................................68

Conclusion....................................................... 70

LIST OF REFERENCES ................................................... 72

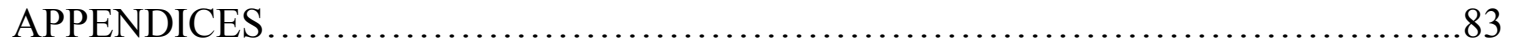

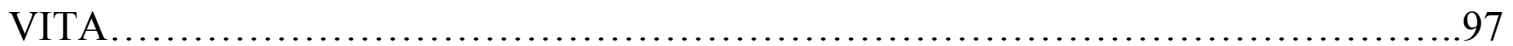




\section{LIST OF TABLES}

TABLE

PAGE

1. Factors Associated with the Big 5 Taxonomy................................ 14

2. Validity Scores from Barrick and Mount (1991)............................. 17

3. Validity Scores from Barrick, Mount, and Judge (2001)........................... 18

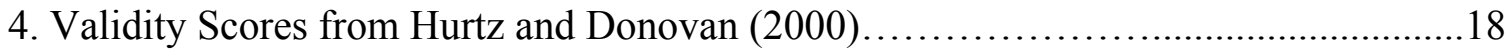

5. Self-Efficacy and Work Performance Outcomes..............................26

6. Terms Associated with Mental Models........................................ 31

7. Correlations among Hypothesized Variables.......................................49

8. Results of Mediation Analyses for Content Quiz Performance.............................53

9. Results of Mediation Analyses for Final Score Performance........................54

10. Chi-Square Test of Personality Scale......................................55

11. Descriptive Statistics and Skewness of Personality Variables.....................55

12. Analysis of Variance of Personality Scores by Gender..........................57

13. Analysis of Significant Findings controlling for Cumulative GPA..................58 


\section{Chapter 1}

\section{Introduction}

\section{Personality and Performance}

Relationships between personality and performance are well established in the management literature. Research spanning the past 100 years has looked into the relationship linking dispositional qualities of the individual to performance (Barrick, Mount, \& Judge, 2001; Judge \& Ilies, 2002). This line of research has continued to progress with evolving conceptualizations of disposition that include the five-factor model (FFM) and Self-Efficacy (discussed below). Concomitantly, multivariate relationships, which posit personality working together with other variables, (e.g. goal setting, task performance, self-deception, and work environment) have gained popularity in better explaining the link between personality and performance (Barrick, Mount, \& Strauss, 1993; Gellatly, 1996; Martocchio \& Judge, 1997; Westerman \& Simmons, 2007).

Central to the progression of this line of research is the continuing investigation of the true nature of the relationship between personality and performance. For example, does personality directly influence performance, or is it mediated by other variables indirectly influencing performance? Relationships have been posited and proven to be statistically significant from both a direct effect relationship and an indirect (i.e., mediating or moderating) relationship. Overall, personality has been shown to influence performance on its own as well as in tandem with other variables (Beaty, Cleveland, \& Murphy, 2001; Digman, 1990; Gellatly \& Irving, 2001; Goldberg, 1990; Hochwater, Witt, \& Kacmar, 2000; Hurtz \& Donovan, 2000). 
Researchers including Digman (1990), Goldberg (1990), Hurtz and Donovan (2000), McCrae and Costa (1987), and, Motowildo and Van Scotter (1994) have all published empirical support for personality having a direct influence on performance. Their contentions hold that personality factors act as independent variables and have a statistically significant effect on performance, or that personality, as a stand-alone variable, is a significant predictor of performance. Other researchers including Barrick and Mount (1993), Beaty, Cleveland, and Murphy (2001), Gellatly and Irving (2001), and Hochwater, Witt, and Kacmar (2000), counter this contention by identifying potential indirect, mediating and moderating variables in the personality-performance relationship. These studies have empirically investigated some but not all important mediating variables in the study of the personality-performance relationship. This study continues this line of research by investigating the inclusion of mental models in the personalityperformance relationship. As referenced above, mediation has been shown to add significant specification and understanding to the somewhat tenuous personalityperformance relationship (Morgeson, Campion, Dipboye, Hollenbeck, Murphy, \& Schmitt 2007; Ones, Dilchert, Viswesvaran, \& Judge, 2007; Tett \& Christiansen, 2007).

\section{Indirect Approaches to the Personality-Performance Relationship}

As discussed previously, there has been an increasing, albeit limited, trend in research using mediating variables in investigating the personality-performance relationship. The reasons for this growing trend include efforts to more effectively conceptualize the personality-performance relationship as well as to respond to several calls for research aimed at investigating potential indirect relationships in the personalityperformance relationship. Some of these calls for research include Westerman and 
Simmons (2007) who stated, "Research to date has disproportionately focused on the direct linkage between personality and performance” (p. 291). Hurtz and Donovan (2000) added to this claim by stating, "If we are truly to understand the relationship between personality and job performance, we must move beyond the bivariate (i.e., personalityperformance) relationship and toward specifying the intervening variables that link these domains" (p. 877).

Further pressure came from Barrick, Mount, and Judge (2001) in an address to future research stating, "The need for a moratorium of the meta-analytic type review... and recommend that researchers embark on a new research agenda designed to further our understanding of personality-performance linkages" (p. 1). In an attempt to address the gap previously mentioned in research as well as to add to the body of knowledge regarding the personality-performance relationship, this investigation further tests potential indirect, mediating variables in the personality-performance relationship.

\section{Validity in the Personality-Performance Relationship}

One of the major shortfalls for almost all dispositional effects on performance has involved relatively small effect sizes or minimal influencing power of disposition on performance. In a research study aimed at investigating the validity of personality measures in personnel selection, Morgeson et al. (2007) found insufficient validity in the use of personality measures for personnel selection decisions. The researchers argued that the inability of the Big 5 to accurately predict performance outcomes was due to low predictive power of the Big 5 in their relationship to performance outcomes. In response to Morgeson et al.'s findings, Ones, Dilchert, Viswesvaran, and Judge (2007), and Tett and Christiansen (2007) countered with the finding that personality was a valid predictor 
of performance, and that the original validity coefficients published in a seminal study by Barrick and Mount (1991) actually underestimated the relationship between personality and performance. These competing views have created rejoinder discussions arguing the true validity of personality measures in predicting performance, which continue today.

Considering the two glaring issues in the relationship between personality and performance (i.e., the need for indirect relationships and low validity), the current study addresses these problems by introducing a potential mediating variable to the relationship between personality and performance. Using similar approaches employed in previous research, this study examines the predictive power associated with introducing mental models to the personality-performance relationship. Mental models are defined as cognitive structures or networks of associations between concepts (e.g. terms or words) in an individual's mind (Ward \& Reingen, 1990). The contention in this study is that individuals with different personality types will be more or less likely to form accurate mental models; therefore, positively impacting performance. If these contentions hold, the findings from this study could lead to a better understanding of the way in which individuals form mental models and to a greater understanding of how personality truly impacts organizational performance.

\section{Personality Conceptualized through the Big 5 Model}

If a consensual structure of personality traits is to emerge, the five-factor model is probably it (Judge \& Ilies, 2002). Many researchers agree that the Big 5 Model has come to provide the most widely accepted structure of personality with the majority of personality research over the last twenty years focused on the Big 5 traits of personality (Judge \& Ilies, 2002). The Big 5 Model has distilled personality into five distinguishable 
traits such that other notions of personality merely represent some combination of these pure dimensions. Riding large-scale acceptance in the literature, the Big 5 model has been used as a common conceptualization of personality to predict a host of performance outcomes (Hurtz \& Donovan, 2000). Given the popularity of this conceptualization and its presence in most current studies investigating broad personality traits, the current study conceptualizes personality through the Big 5 taxonomy. For the purposes of the current study, the Big 5 taxonomy, the Big 5 model, the Big 5 traits, and the "Big 5 " will be used interchangeably to refer to the same conceptualization set forth by Barrick and Mount (1991), Goldberg (1990), and McCrae and Costa (1987).

The Big 5 taxonomy of personality traits, including conscientiousness (C), extraversion (E), agreeableness (A), emotional stability (ES), and openness to experience (OE) were introduced by Barrick and Mount (1991), and encompass five personality traits aimed at synthesizing the much broader study of personality. Evidence that personality, and, specifically, the Big 5, remains a valid predictor of performance can be found in work done by Barrick, Mount, and Judge (2001), and Hurtz and Donovan (2000), who show continuing support for the Big 5 traits in predicting performance. In the studies above, the five-factor taxonomy of personality consistently emerged as a valid and generalizable measure of personality. Of specific interest to the current study are the Big 5 traits of conscientiousness, extraversion, openness to experience, and emotional stability, which have been linked to performance across a variety of organizational measures (Barrick \& Mount, 1998; Costa \& McCrae, 1988; McCrae \& Costa, 1985, 1987). Support for the role of these traits in the current study is further discussed in the literature review below. 


\section{General Self-Efficacy and Performance}

Another well supported dispositional predictor of performance is General SelfEfficacy (GSE), a construct that looks at an individual's own perceived ability to do well on tasks. Seen as a motivational trait "perceived self-efficacy is concerned with judgments of how well one can execute courses of action required to deal with prospective situations" (Bandura, 1982, p. 122). According to Wood and Bandura (1989b), self-efficacy is further defined as “a belief in one's ability to mobilize the motivation, cognitive resources, and courses of action needed to meet situational demands" (p. 364). Support for the inclusion of GSE in the current study stems from the substantial amount of research linking GSE to performance (Judge, Erez, \& Bono, 1998). GSE has been consistently linked to performance, and has often been included in studies investigating the impact dispositional effects have on performance (Barrick \& Mount, 1991; Barrick, Mount, \& Strauss, 1993; Costa \& McCrae, 1992; Gellatly, 1996; Stajkovic \& Luthans, 1998). Examples of performance outcomes linked with GSE include: attitudes (Saks, 1995), training proficiency (Martocchio \& Judge, 1997), and on-the-job performance (Stajkovic \& Luthans, 1998). Furthermore, dispositional research has found significant relationships between the Big 5 and GSE in the prediction of performance (Judge \& Ilies, 2002). These high inter-correlations warrant investigating GSE in the current study.

Distinction should be made between general self-efficacy (GSE) seen as a motivational, dispositional trait (Eden, 1988; Judge, Erez, \& Bono, 1998; Judge, Locke, \& Durham, 1997), and state or specific self-efficacy (SSE) seen as a situationally derived perception of ability (Gist \& Mitchell, 1992; Lee \& Bobko, 1994). This distinction is 
important when conceptualizing GSE as a dispositional factor as opposed to the more situationally influenced SSE. Given the success of GSE in predicting performance, the current study includes the dispositional trait GSE as a second exogenous variable in the hypothesized model. In other words, GSE is hypothesized to impact performance through an indirect, mediating relationship, where mental models are the mediator. The potential role that GSE may have on mental model formation and the hypothesized relationship between GSE and performance are discussed below.

\section{Mental Models}

Mental models have come to encompass a myriad of conceptualizations and forms all of which center around the manner in which individuals organize and retain information for later recall and use (Klimoski \& Mohammed, 1994). At the simplest level, a mental model is a cognitive structure or network of associations between concepts (e.g. terms or words) in each individual's mind (Ward \& Reingen, 1990). Langan-Fox, Code, and Langfield-Smith (2000) add to this definition by stating, "Mental models incorporate a network of associations between domain concepts, whereby humans generate description and form" (p. 243). In other words, mental models constitute human generated relationships between specific concepts or terms, which are used to describe and illustrate individuals' understanding of those terms. Other terms often used in describing mental models include cognitive maps (Axelrod, 1976; Ford \& Hegarty, 1984), belief structures (Rumelhart, 1984), and scripts (Abelson, 1976).

\section{The Big 5, GSE, and Mental Models}

Hogan, Hogan, and Roberts (1996) conceptualized personality traits as stable individual differences explaining an individual's disposition to particular patterns of 
behavior, cognitions, and emotions. If stable individual differences are associated with changes in individual cognition, then investigating the role of the Big 5 and GSE in mental model formation is warranted in the study of human performance. In support of this contention, a study by Bidjerano and Yun Dai (2007) found conscientiousness to be associated with dependability, and the ability to plan, organize and persist, while openness to experience was associated with a positive attitude towards challenging learning experiences. These findings lend initial credence to the notion that the manner in which individuals take on information is impacted by individual differences in traits.

Self-efficacy has also been linked with the manner in which individuals approach and execute learning behavior (Pintrich and Degroot, 1990). Of particular interest to the current study is the notion that individual's belief in their capacity to understand the material presented may influence the mental model formed by the individual. In a study done by Pintrich and Degroot (1990), higher levels of individual self-efficacy were associated with higher levels of self-regulated learning strategies and a greater usage of cognitive strategies by those individuals. These findings provide support for the hypothesized relationship between GSE and mental model formation.

\section{Mental Models and Performance}

As jobs have evolved and progressed so to have the knowledge and cognitive requirements needed for these jobs. In research done by Morgeson, Delaney-Klinger, and Hemingway (2005) cognitive ability and job-related skill were found to be positively related to job role breadth. The researchers also found that job role breadth mediated the relationship between job-related skill and performance. Current organizational jobs demand higher levels of knowledge, as well as the capacity to access multiple types of 
knowledge (i.e., job breadth) in an efficient and effective way. Given that the manner in which knowledge is organized (above and beyond the knowledge itself) impacts the effective use and recall of that information (Cuevas, Fiore, \& Oser, 2001; Fiore, Cuevas, \& Oser, 2003; Scielzo, Fiore, Cuevas, \& Salas, 2002), investigation into the impact mental model formation has on performance is warranted.

In work citing the mental model-performance relationship, Scielzo et al. (2002) state:

Training systems that enable learners to build an appropriate mental model of the relations between concepts have been shown to encourage the acquisition of knowledge structures more similar to an expert model. (p. 566)

Scielzo et al. make reference to the use of an expert model, positing that mental models more similar to that of an expert mental model are linked with higher performance. Speaking to expert mental models, Langan-Fox, Wirth, Code, Langfield-Smith, and Wirth (2001) state:

Ordinarily, a manager or supervisor (expert) should possess knowledge and experience that surpass that of any of his/her subordinates. Thus, a manager's (or expert's) mental model could be considered to represent the 'ideal' model of how the team should be functioning in order for the business unit to be successful. (p. 100-101)

If supervisors' (expert) mental models encompass more 'ideal' mental models, and those mental models are linked to higher performance, then investigating the manner in which mental models are formed is warranted. Langan-Fox et al. (2001) go on to state,

The notion that similarity to a referent or expert mental model is associated with superior performance has been consistently supported in a number of domains, which include education (Gillian, Breddin, \& Cooke, 1992) electronics (Rowe, Cooke, Hall, \& Halgren, 1996), computer programming (McDonald, Papp, \& McDonald, 1990), and air traffic control (Vortec, Edwards, \& Manning, 1994). (p. 101) 
Significant relationships have been shown to exist between the Big 5/GSE and performance, and between mental models and performance. As such, this study poses the question if mental model formation mediates the relationship between the Big 5 and GSE, and performance. This study addresses the gap in research by examining the relationship between personality (i.e., the Big 5 and GSE), mental model formation, and performance. If variations in personality types can be shown to impact the manner in which individuals understand and use information (i.e., mental models), which then impact performance, then implications to organizational performance in the realms of training, knowledge transfer, and knowledge delivery could be wide spread. Furthermore, if clear distinctions can be made between personality types in regards to how individuals form mental models, then changes to the way in which knowledge is delivered can be addressed to better suit effective performance across different personality types.

Mediation is said to occur when the causal effect of some variable $\mathrm{X}$ on outcome $\mathrm{Y}$ is explained by some intervening variable M (Shrout \& Bolger, 2002). The goal of most mediation analysis is to decompose or bring to light components that reveal the true nature of causal mechanisms (Shrout \& Bolger, 2002). Given the calls for research to further investigate intervening variables and the added specification provided by such investigations, the current study investigates the mediating role of mental models in the personality-performance relationship. When intervening variables account for the association of distal variables with an outcome, better explanation is provided (Shrout \& Bolger, 2002). In other words, adding mental model formation as a mediator in the personality-performance relationship may better explain the causal mechanisms by which 
personality impacts performance, thereby increasing the predictivenes of personality on performance.

\section{Summary of Research Question}

Figure 1 shows the hypothesized mediating model investigated in the current study. The Big 5 traits and general self-efficacy are expected to impact mental model formation as dispositional exogenous variables. Differences in the Big 5 traits are expected to influence the manner in which individuals form mental models through differences in the cognitive processes and organization of new information. Furthermore, differences in mental model formation are expected to influence subsequent performance through the formation of more or less accurate mental models of new information, thereby impacting performance. As such, the central research of this study is: does mental model formation mediate the effect of personality and GSE on performance? 


\section{Chapter 2}

\section{Literature Review and Hypotheses}

\section{Relating Disposition and Performance}

The model in Figure 1 reflects the expected relationship between disposition, mental models, and performance. Disposition is defined based on previous research included in the current literature review as the Big 5 personality taxonomy and general self-efficacy. Mental models (MM) are included as a mediating variable in the relationship between the Big 5, GSE and performance. The following section discusses the relationships reflected in Figure 1. This study moves away from the direct effect model as described in previous research (Figure 2) and towards the hypothesized model (Figure 1).

\section{Figure 1}

\section{Hypothesized Mediating Model*}

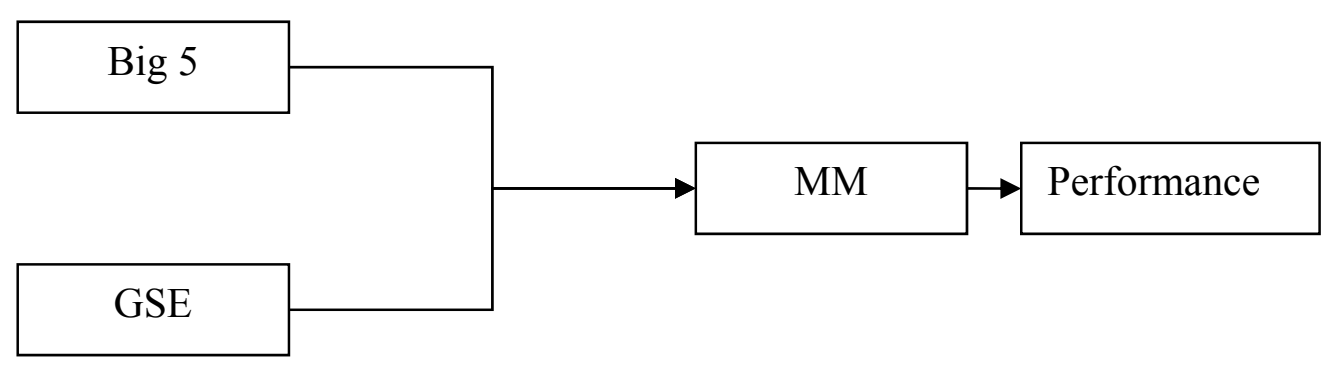

\footnotetext{
* Illustrated model showing the hypothesized mediating effect mental models has on the personality-performance relationship
} 
Figure 2

Model of supported relationships in past research*

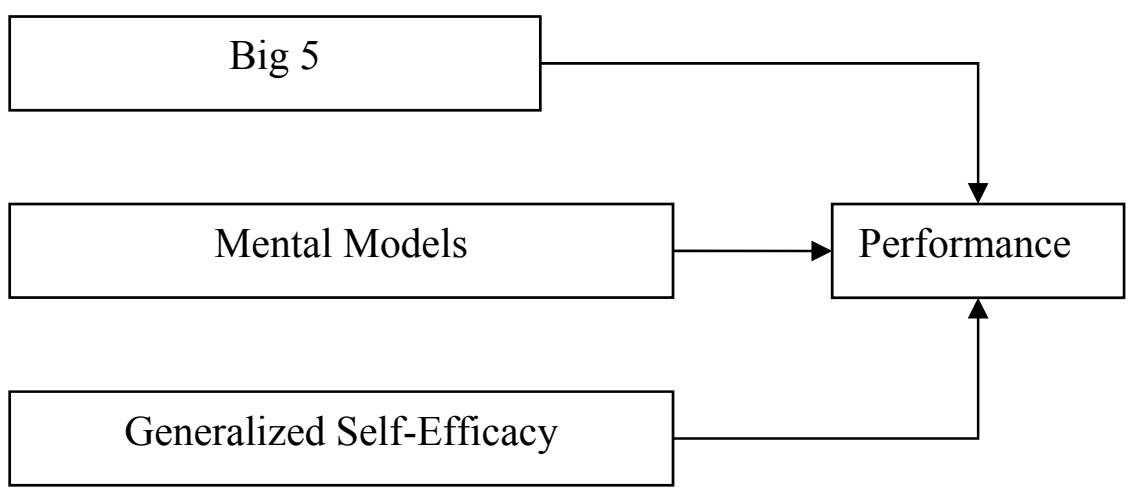

\section{* Illustrated model showing the supported direct effect relationships between disposition, mental models, and performance.}

\section{Personality and the Big 5}

Personality has been linked with performance outcomes. As examples, Barrick and Mount (1991), Barrick, Mount, and Judge (2001), Behling (1998), Hurtz and Donovan (2000), and Mount and Barrick (1995) found that personality has statistically significant influence on performance outcomes including overall performance, teamwork, and training proficiency. Within personality research, the Big 5 taxonomy has surfaced as one of the most popular conceptualizations to date. Introduced by Barrick and Mount (1991), the five-factor model is a proposed taxonomy of broad personality traits aimed at synthesizing the lengthy list of identified personality characteristics. The Big 5 include: conscientiousness, agreeableness, extraversion, openness to experience, and emotional stability. Conscientiousness is defined as the trait of being more likely to be orderly and decisive, to be autonomous on goal-setting behavior, to show greater ability to cope with 
time management issues and stress, and to generally strive for continuous performance improvement. Agreeableness is defined as the trait of being more trustworthy and as possessing higher levels of integrity. Extraversion is characterized by personalities with a need for stimulation and high externally oriented activity, as well as being high in sociability. Openness to experience is defined as being intellectually curious, imaginative, and open to possibilities. Emotional stability is defined as being less depressed, insecure, and anxious (Barrick and Mount, 1991). Barrick, Mount, and Judge (2001) validated the five factors by associating each with the terms listed in Table 1.

TABLE 1

FACTORS ASSOCIATED WITH THE BIG 5 TAXONOMY

\begin{tabular}{ll}
\hline Conscientiousness & - Dependability \\
& - Achievement Striving \\
\hline Agreeableness & $\bullet$ Planfulness \\
& - Trustfulness \\
& - Affability \\
\hline Extraversion & $\bullet$ Sociability \\
& $\bullet$ Dominance \\
& $\bullet$ Ambition \\
& $\bullet$ Positive Emotionality \\
& $\bullet$ Excitement Seeking \\
\hline Openness to Experience & $\bullet$ Intellectance \\
& $\bullet$ Creativity \\
& $\bullet$ Unconventionality \\
& $\bullet$ Broad-mindedness \\
\hline Emotional Stability & $\bullet$ Lack of Anxiety \\
& $\bullet$ Hostility \\
& $\bullet$ Depression \\
& $\bullet$ Personal Insecurity \\
\hline
\end{tabular}




\section{The Big 5 and Performance}

Since its introduction, the Big 5 has been the most widely used taxonomy studying the linkage of personality to performance (Barrick \& Mount, 1998; Costa \& McCrae, 1988; McCrae \& Costa, 1985, 1987). In their seminal work, Barrick and Mount (1991) used five occupational types and three criterion types as dependent variables in testing the influence of the Big 5 traits on performance. The five occupational types included professional, police, managers, sales, and skilled/semi-skilled. The three criterion types included job proficiency, training proficiency, and personnel data.

Of the five traits, conscientiousness and emotional stability have been shown to have the highest positive correlation with overall conceptions of performance and valid predictors regardless of criterion type or occupational group (Anderson \& Viswesveran, 1998). Other traits have been supported with more specific measures of performance. For example, conscientiousness and emotional stability have been linked with performance measures related to teamwork (Hough, 1992), and training proficiency (Barrick \& Mount, 1991). The trait of agreeableness has been linked to service orientation performance (Barrick, Mount, \& Judge, 2001), while extraversion and openness to experience have been linked with performance in training initiatives (Barrick \& Mount, 1998).

It should be noted that between the initial work on the Big 5 by Barrick and Mount (1991), Goldberg (1990), and McCrae and Costa (1987), fifteen meta-analyses had been conducted to investigate the initial Barrick and Mount (1991) findings. While this en masse publication of meta-analyses prompted a call for a moratorium on further meta-analyses, it also captured a decade's worth of research linking the Big 5 to performance. In the end, initial findings were upheld, showing conscientiousness to be a 
valid predictor across all five occupational groups, with emotional stability having less support when linked to the professional occupational group. Furthermore, extraversion maintained its predictiveness across two occupational groups (i.e., managers and sales representatives), with little support for agreeableness found in the same occupational groups. Lastly, openness to experience and extraversion were upheld as valid predictors

of performance using the training proficiency criterion (Hurtz \& Donovan, 2000). Central to this study, four of the five traits (i.e., conscientiousness, extraversion, openness to experience, and emotional stability) have shown strong predictive power in overall and training-related performance measures (Barrick and Mount, 1991). Conscientiousness was supported as the strongest predictor of performance outcomes including student GPA, sales outcomes, and team performance (Judge \& Ilies, 2002; Salgado, 2003; Westerman \& Simmons, 2007). Lastly, Hogan, and Holland (2003) published findings supporting both agreeableness and extraversion as significant predictors of performance.

\section{The Validity of the Big 5}

While the majority of this section focuses on the Big 5 and its positive links with performance, there is research that posits personality, and more specifically the Big 5 , as non-significant in predicting work-related outcomes and performance. These studies posit low and insignificant statistical relationships between personality and performance. For example, Ones, Dilchert, Viswesvaran, and Judge (2007) cite a stream of research dating back to the seminal work of Guion and Gottier (1965) who expressed the ineffectiveness of personality in predicting performance and other job related measures. One of the more recent iterations of this continuing dialogue can be found in work done by Morgeson et 
al. (2007) who argue that the inability of personality to predict with personnel selection is due in large part to both a lack of predictive validity and faking in assessment.

As is always the case with dispositional variables, low validity scores and effect sizes are central to the debate. Since both sides have produced supporting research, the argument still remains regarding the true validity of direct effect relationships involving personality and performance. Table 2 reflects the results of the work of Barrick and Mount (1991) regarding the Big 5 personality traits and job performance. Table 3 displays the work of Barrick, Mount, and Judge (2001), which was based on various occupational groups. Table 4 shows the published $\mathrm{r}$ scores and $\mathrm{p}$ values associated with the five factors and job performance from one of the most recent and comprehensive meta-analyses done by Hurtz and Donovan (2000).

TABLE 2

\section{VALIDITY SCORES FROM BARRICK AND MOUNT (1991)}

\begin{tabular}{lcc}
\hline \multicolumn{1}{c}{ Trait } & Correlated r & p value \\
\cline { 2 - 3 } Conscientiousness & .13 & .22 \\
\hline Extraversion & .08 & .13 \\
\hline Agreeableness & .04 & .07 \\
\hline Emotional Stability & .05 & .08 \\
\hline Openness to Experience & .03 & .04 \\
\hline
\end{tabular}


TABLE 3

VALIDITY SCORES FROM BARRICK, MOUNT, AND JUDGE (2001)

\begin{tabular}{lcc}
\hline \multicolumn{1}{c}{ Trait } & Observed r's & $\underline{\mathrm{p} \text { value }}$ \\
\hline Conscientiousness & $.09-.13$ & $.20-.23$ \\
\hline Extraversion & $-.05-.11$ & $-.09-.15$ \\
\hline Agreeableness & $.00-.06$ & $.00-.10$ \\
\hline Emotional Stability & $-.07-.06$ & $-.13-.08$ \\
\hline Openness to Experience & $-.05-.05$ & $-.08-.08$ \\
\hline
\end{tabular}

TABLE 4

VALIDITY SCORES FROM HURTZ AND DONOVAN (2000)

\begin{tabular}{lcc}
\hline \multicolumn{1}{c}{ Trait } & Correlated r & p value \\
\hline Conscientiousness & .14 & .20 \\
\hline Extraversion & .06 & .09 \\
\hline Agreeableness & .07 & .11 \\
\hline Emotional Stability & .09 & .13 \\
\hline Openness to Experience & .04 & .06 \\
\hline
\end{tabular}

Although sufficient investigation and meta-analytic research have been done to empirically support the relationship between the Big 5 and performance, there remains enduring and relatively low predictive power in these relationships warranting continued investigation for both direct and indirect relationships. The following section will discuss mediation as a means to explain the personality and performance relationship through cognitive mechanisms employed by certain personality types and their subsequent impact on performance. 


\section{Mediation for the Personality-Performance Relationship}

Mediation is said to occur when the causal effect of some variable $\mathrm{X}$ on outcome $\mathrm{Y}$ is explained by some intervening variable $\mathrm{M}$ (Shrout \& Bolger, 2002). In line with past research referenced above, mental model formation may better explain the causal link between personality and performance by better defining the mechanism by which personality impacts performance. Support for the use of mediation in explaining the personality-performance relationship can be found in research done by Barrick, Mount, and Strauss (1993), who found that goal setting activities mediated the relationship between conscientiousness and sales performance. Other indirect investigations of the personality-performance relationship include Gellatly (1996), who investigated the effect of task performance as a mediating variable. The researchers found that the relationship between conscientiousness and performance was mediated by performance expectancy and goal choice. Still other studies including Gellatly and Irving (2001) found that job autonomy moderated the relationship between extraversion, agreeableness and performance. Other important mediators found include, self-deception (Martocchio \& Judge, 1997), and work environment (Westerman \& Simmons, 2007). Beyond findings supporting the impact of personality on performance, further impetus for the investigation of indirect relationships came from a call for research aimed at investigating process variables that might stipulate the relationship between personality and performance. Most notably Barrick, Mount, and Judge (2001), who called for a complete moratorium on the types of studies using meta-analytic methods and recommended a new agenda in the approach to understanding the personality-performance relationship. In the current study, the process variable mental models is included as a potential mechanism by which 
different personality types may organize and structure new information; thereby impacting performance related to that new material.

\section{The Big 5 and Mental Models}

With the majority of research finding tenuous support for the direct effect of personality on performance, coupled with the increasing use of intervening variables in investigations of the personality-performance relationship, mental models (discussed below) offer a potential path by which to strengthen the relationship between personality and performance. As was cited in studies above, indirect, mediating variables can help explain the relationship between personality and performance. Multiple studies, previously cited, have shown support for the role mediating variables play in better specifying the personality-performance relationship. Based on these findings, the Big 5 traits conscientiousness, emotional stability, openness to experience, and extraversion are posited to work through mental model formation in influencing performance.

Since much of the interest in mental models stems from the idea that the manner in which information is represented influences how it is eventually processed (LanganFox et al., 2001), personality differences and their impact on individual's representations of information is warranted. Furthermore, if mental models act as a source of predictive and explanatory information that denotes the particular types of knowledge associated with a set of purposes. (Langan-Fox et al., 2001, p. 100), then investigating the antecedents that influence mental model formation is important to management research. If mental models encompass some cognitive, categorized understanding of information by the individual, then dispositional differences that include planfulness, intellectance, 
broad-mindedness, sociability, and personal security may impact the formation of individual mental models (Table 1).

Building on the term 'cognitive representation' used by Langan-Fox et al. (2001), Klimoski and Mohammed (1994) incorporate terms including categories, schemas, cognitive maps, and scripts to describe mental models. Furthermore, if mental models are shown to impact performance, then understanding the influencing role of personality in mental model formation is critical. For example, work done by Langan-Fox et al. (2001) stated that individual mental models might impact organizational performance vis-à-vis the similarity between a subordinate's mental model and that of a supervisor's (expert) mental model. When considering the processes by which mental models form, one could see the potential influence dispositional differences may have on mental model formation. The Big 5 traits, conscientiousness, emotional stability, openness to experience, and extraversion are hypothesized to effect individual mental model formation through different tactics and strategies used in processing information in that higher levels of these traits will positively influence accurate (i.e., as compared to an expert's mental model) mental model formation.

\section{Hypothesized relationships for the Big 5, Mental Models and Performance}

Initial support for the relationship between personality traits and mental models can be found in work done by Messick (1984) who stated that underlying personality traits may be responsible for and create consistency in information processing, thus impacting performance. In support of this contention, a study by Geisler-Brenstein, Schmeck, and Hetherington (1996) found a positive relationship between conscientiousness and methodic, analytic learning. In other words, individuals high in 
conscientiousness were more methodic and organized in the manner in which they retained information. In accordance with notions of mental model formation defined in the current study the researchers also found intellect to be associated with a deep and elaborative approach to learning. This supports the notion that high intellect individuals are more likely to form more effective and accurate mental models through greater understanding of the material.

Vermetten, Lodewijks, and Vermunt (2001) found agreeableness to be correlated with positive effort and surface (reproductive) learning, stating, "agreeableness involved compliance and cooperativeness, which made agreeable individuals more likely to consolidate their learning and regulate their study habits to fit external demands" (p. 165). Stated differently, highly agreeable individuals may be more likely to organize information based on external, social cues. Regarding emotional stability, Eysenck (1967) linked neuroticism with a lack of effective cognitive skills, which negatively impacted performance. Neuroticism (low emotional stability) was further linked with poor critical thinking skills, analytical ability, and conceptual understanding (Matthews \& Zeidner, 2004). These findings support the contention that higher levels of neuroticism may limit the proper organization of information thereby leading to inaccurate mental model formation.

Analysis of the terms most commonly associated with the traits hypothesized in the current study point to the potential relationships between the Big 5 and mental model formation. For example, conscientiousness, often associated with achievement striving and planfulness may impact the tactics and manner in which individuals retain and organize information. Extraversion, associated with positive emotionality and sociability 
may impact individual's level of engagement and involvement in learning environments, thereby influencing mental model formation. Lastly, emotional stability and openness to experience encompass ideals of broad-mindedness, intellectance, and a lack of anxiety, which, coupled with studies cited above, may impact the manner and tactics used by individuals to retain and organize information.

Additional theoretical support for the relationship between personality and mental model formation can be found in work done by Basuto, Prins, Elshout, and Hamaker (1998), who looked at the relationships between each of the Big 5 traits and three distinct types of learning (i.e., reproduction-directed learning, application-directed learning, and meaning-directed learning). Reproduction-directed learning was characterized by focusing only on what is learned to pass the test specifically. Application-directed learning focused more on real-world application of the material. Lastly, meaning-directed learning involved actual understanding of the meaning in order to more critically understand and apply the material. Basuto et al. (1998) found that extraversion and conscientiousness were associated with all three types of learning, with conscientiousness being negatively correlated with undirected-learning. In other words, conscientiousness positively impacted all learning initiatives that provided ample direction, but actually hindered learning when direction was not provided, while extraversion was found to positively impact all types of learning. This adds further impetus to the idea that engaged and positive individuals are more likely to take more from a learning environment. Basuto et al. (1998) also found openness to experience to be positively associated with meaning and directed-learning, while neuroticism was positively correlated with undirected-learning and negatively related with meaning and reproduction-directed 
learning. These results are in line with the concept that high levels of openness to experience are associated with a broad-minded view, and therefore more open to learning, while high levels of neuroticism limit proper organization of material and learning.

In their study, agreeableness was positively correlated with reproduction and application-directed learning. Furthermore, individuals high in agreeableness were linked with higher levels of cooperation and compliance (Basuto et al., 1998). It could be argued that higher levels of cooperation and compliance would lead to greater reproductivelearning as it relates to mental models. It is also possible that highly agreeable individuals may be more likely to accept pre-conceived understandings of content material. Based on both the consideration of the terms most associated with the hypothesized traits, as well as significant support linking the Big 5 traits to both cognitive and learning tactics used by individuals, the current study hypothesizes that higher levels of the Big 5 traits conscientiousness, emotional stability, extraversion, and openness to experience will lead to more accurate mental model formation.

\section{General Self-Efficacy}

Along with the Big 5 and its documented influence on performance, generalized self-efficacy (GSE) is another dispositional variable equally well-documented in its effect on performance (Bandura, 1977; Judge \& Bono, 2001; Pajares, 1996). Introduced by Bandura (1977), self-efficacy is described as a belief about the probability that one can successfully execute some future action or task or achieve a positive result. In line with Bandura's (1977) definition of self-efficacy, Judge, Erez, and Bono (1998) defined GSE as an individual's perception of his or her ability to perform across a wide variety of 
different situations. The findings of Chen, Gully, and Eden (2004) further support general self-efficacy as an important trait by linking GSE to individual differences regarding motivation, attitudes, learning, and task performance.

\section{GSE vs. SSE}

Given that this study investigates GSE as an independent variable, it is important to distinguish GSE from SSE or situational self-efficacy. While GSE is considered to be dispositional and stable in nature, SSE is seen as a more task or situationally specific form of self-efficacy. Chen et al. (2004) add to this distinction by stating, "GSE is distinguishable from the concept of self-efficacy because, whereas self-efficacy is a relatively malleable, task-specific belief, GSE is a relatively stable, trait-like, generalized competence belief" (p. 376). This distinction is critical to the role GSE plays as a dispositional variable, rather than a situational variable. Stated differently, GSE is said to capture enduring individual differences in the tendency to view oneself as capable or incapable of meeting task demands in a wide variety of situations (Chen, Casper, \& Cortina, 2001). Further support for the construct of general self-efficacy as a trait can been found in work by Eden and Aviram (1993), Eden and Zuk (1995), and Sherer, Maddux, and Mercandante (1982) who posit generalized self-efficacy as a stable cognition that people hold and carry with them.

\section{General Self-Efficacy and Performance}

One of the most consistent relationships made regarding GSE involves its role in influencing performance. Just a few of the performance measures linked with GSE include self-set goals (Locke \& Latham, 1990), state anxiety (Martocchio, 1992), the formulation of effective analytical strategies (Wood \& Bandura, 1989a), and overall 
performance (Stajkovic \& Luthans, 1998). In a meta-analysis done by Judge and Bono (2001), generalized self-efficacy was shown to have a statistically significant and strong correlation with job performance. Judge and Bono (2001) further explained that while conscientiousness was suggested as the primary dispositional predictor of performance, generalized self-efficacy displayed an equally powerful relationship with job performance. These results support the influence that GSE has on job performance being equal to that of conscientiousness. In a meta-analysis done by Stajkovic and Luthans (1998), the linkage between self-efficacy and varied work performance outcomes was demonstrated. Table 5 summarizes the important associations between GSE and work performance in the meta-analysis.

TABLE 5

SELF-EFFICACY AND WORK PERFORMANCE OUTCOMES

\begin{tabular}{ll}
\hline Work Performance Outcomes & Study \\
\hline Adaptability to technology & Hill, Smith, \& Mann (1987) \\
\hline Coping with career & Stumpf, Brief, \& Hartman (1987) \\
\hline Managerial idea generation & Gist (1989) \\
\hline Managerial performance & Wood, Bandura, \& Bailey (1990) \\
\hline Skill acquisition & Mitchell, Hopper, Daniels, George-Falvy, \& James \\
& $(1994)$ \\
\hline Newcomer adjustment to & Saks (1995) \\
organization & \\
\hline
\end{tabular}

Not all research on GSE supports a positive link with performance. According to a study by Vancouver, Thompson, Tischner, and Putka (2002), self-efficacy was shown to negatively effect performance through decreases in intrapersonal resource allocation. 
The researchers argued that repetitive mastery or success of a task leads to a decrease in the amount of resources one may dedicate to subsequent tasks. Their contention held that repetitive successes would lead to a sense of over-confidence causing a decline in performance in subsequent tasks.

While the above findings are relevant to self-efficacy research, the focus was mostly on SSE or situational self-efficacy. Mastery of a given task, over-confidence, and motivational spillover play reciprocal roles in the relationship between SSE and performance, yet they are mitigated when considering GSE (Bosscher \& Smit, 1998). This is not to say GSE is immune to reciprocal influences, just that it would likely take multiple, various successes or failures across multiple domains to alter one's GSE.

Adding to this distinction, Bosscher and Smit (1998) state:

Self-efficacy theory emphasizes domain-specificity, implying that the strongest relationships exist between beliefs regarding a specific behavior performance and performance of that behavior. However, various and numerous experiences of failure and success in different domains of functioning may generate more generalized beliefs of self-efficacy that have explanatory value as well. (p. 340)

Furthermore, Bandura and Locke (2003) counter the negative effects of GSE on performance by stating:

Vancouver et al.'s (2001) proclaimed discovery of negative efficacy effects is nothing new. Self-efficacy theory adopts a conditional view regarding negative effects of an elevated sense of personal efficacy. For example, the functional value of high perceived self-efficacy differs in preparatory and performance aspects of functioning. In preparing for challenging endeavors, some self-doubt about one's performance efficacy provides incentive to acquire the knowledge and skills needed to master the challenges. (p. 96)

\section{General Self-Efficacy and the Big 5}

Significant correlations exist between GSE and the Big 5. In research performed by Judge and Ilies (2002), extraversion was a moderately strong correlate of self-efficacy, 
while conscientiousness was positively correlated with goal setting motivation, expectancy motivation, and self-efficacy motivation. This adds importance to the relationship between the Big 5 and GSE when predicting performance. Big 5 and GSE, traits once considered in isolation, can effectively be brought together for better specification. Judge and Ilies (2002) support this contention with strong and significant multiple correlations (average $\mathrm{R}=.49$ ) between the five-factor model and performance motivation.

In the end, support for the positive effects of GSE on performance outweighs research indicating negative effects. Furthermore, studies empirically demonstrating negative effects of GSE seem to base their results on reciprocal influences in the selfefficacy-performance relationship. Reciprocity should not assume causality in the selfefficacy-performance relationship, negative or positive. Consequently, GSE, as it is conceptualized in the current study, is seen as more resistant to situational influences across tasks. Given the importance and quantity of studies investigating GSE and performance, along with the significant correlations and predictive power associated with the Big 5 and GSE, this study includes GSE in testing potential mediators of the relationship between personality and performance.

\section{Hypothesized Relationships for GSE, Mental Models, and Performance.}

Impetus for the hypothesized relationship between GSE, mental models, and performance can be found in studies that have linked motivational attributes of the individual with the manner and effectiveness in which they acquire and/or request knowledge (Lodewyk \& Winne, 2005; Pintrich \& Degroot, 1990). In looking at academic performance, Lodewyk and Winne (2005) found that individuals with a strong sense of 
academic self-efficacy were more likely to succeed in performing tasks. Lodewyk and Winne (2005) state:

They [students high in self-efficacy] seem to self-regulate more productively (Zimmerman, Bandura, \& Martinez-Pons, 1992; Zimmerman \& Martinez-Pons, 1990), more willingly take on challenging tasks (Bandura \& Schunk, 1981), apply more effort (Schunk, 1983), persist longer despite obstacles (Bandura \& Schunk, 1981; Schunk, 1982), set higher goals (Zimmerman, 1995), experience less anxiety, use more effective tactics and strategies (Pintrich \& DeGroot, 1990), achieve better academic performances (Wigfield \& Eccles, 1992), and cognitively process information more effectively (Berry, 1987; cf. Bandura, 1993). (p. 4)

Of particular interest to the current study are the findings of Pintrich and Degroot (1990) who linked self-efficacy with the use of more effective tactics and strategies, and Berry (1987), who showed that higher self efficacy leads to greater effectiveness in the cognitive processing of information. Given that mental models constitute cognitive representations of information acquired and/or formed by the individual (Klimoski \& Mohammed, 1994), higher levels of GSE are posited to influence the effectiveness of mental model formation through better cognitive processing and more effective tactics used in learning.

Another aspect of interest to the relationship between GSE and mental model formation includes research done by Hayes and Clark (1985), who showed how motivational factors can influence the extent to which recipients seek out, accept, and utilize external knowledge. If individuals with higher levels of GSE are more likely to engage in mental model formation through seeking, accepting, and utilizing external knowledge, then GSE is an important antecedent of mental model formation. Based on these findings, general self-efficacy is hypothesized to positively impact accurate mental model formation through increased self-regulation, tactics, strategies, and cognitive 
processing, thereby impacting mental models. Given that the relationship between GSE and performance is well established, the current study includes and tests the GSEperformance relationship by adding mental model formation as a potential mediating variable. In the current study, individuals who score high on GSE are hypothesized to be more effective in their mental model formation through better knowledge acquisition and tactics in processing new information, thereby leading to higher performance.

\section{Mental Models}

The term mental model has been used across multiple levels and in multiple domains (Langan-Fox et al., 2001). This study incorporates the individual level mental model and considers conceptualizations to that end. One approach to conceptualizing mental models properly would be to look at the terms used synonymously, and often interchangeably, in defining mental models. In speaking to mental model terminology, Klimoski and Mohammed (1994) state, "A plethora of cognitive terminology has been employed to help explain the process by which individuals make sense of their surroundings" (p. 405). Terms and research linked with mental models are listed in Table 6. 
TABLE 6

TERMS ASSOCIATED WITH MENTAL MODELS

\begin{tabular}{lll}
\hline Categories & $\bullet$ & Rosch 1978 \\
& & \\
\hline Belief Structures & $\bullet$ & Fiske \& Taylor 1991 \\
& & \\
\hline Schemas & $\bullet$ & Anderson 1980 \\
& $\bullet$ & Neisser 1976 \\
& $\bullet$ & Rumelhart 1984 \\
\hline Cognitive Maps & $\bullet$ & Axelrod 1976 \\
& $\bullet$ & Ford \& Hegarty 1984 \\
& $\bullet$ & Neisser 1976 \\
& $\bullet$ & Weick \& Bougon 1986 \\
\hline Scripts & $\bullet$ & Abelson 1976 \\
& & \\
\hline Mental Models & $\bullet$ & Johnson-Laird 1983 \\
& $\bullet$ & Rouse and Morris 1986 \\
\hline
\end{tabular}

Mental models are often used in a way that is associated with knowledge, Holyoak, (1984) describes a mental model as a "psychological representation of the environment and its expected behavior" (p. 193). Langan-Fox, Code, and Langfield-Smith (2000) define mental models as, "the knowledge of the interrelationships between the concepts in a domain, acting as a critical variable that influences initial learning, subsequent retention, and later knowledge transfer" (p. 243).

\section{Mental Models and Knowledge Structures}

The basic premise behind knowledge structures comes from well-documented research that explains how the structural, semantic nature of knowledge reflects relationships between units of information, their meaning, and retrievability (Acton, Johnson, \& Goldsmith, 1994; Axelrod, 1976; Ford \& Hegarty, 1984). In other words, beyond the actual terms and knowledge involved, the structure in which the knowledge is 
stored has been shown to affect its usability. Mental model measurement often incorporates structural assessments of terms through pair-wise, similarity, and mapping measures. For a comprehensive review of mental model measurement, reference work done by Langan-Fox, Code, and Langfield-Smith (2000), and Mohammed, Klimoski, and Rentsch (2000).

The notion that information is organized or structured in an individual's memory to facilitate the storage, retrieval, and manipulation of that knowledge, is commonplace in modern psychological and educational theories. The business community has begun to show interest in the mental models and knowledge structures of employees as being an important component of organizational performance. Langan-Fox, Code, and LangfieldSmith (2000) support this trend by stating: "Researchers in a variety of disciplines have sought to elicit and represent mental models. These include education (Morine-Dershimer

et al., 1992; Winitzky, Kauchak, \& Kelly, 1994), and organizational/management settings (Daniels, de Chernatony, \& Johnson, 1995)" (p. 242).

\section{Hypothesized Relationships between Mental Models and Performance}

Showing support for the mental model-performance relationship, Langan-Fox, Wirth, Code, Langfield-Smith, and Wirth (2001) investigated the similarity between an individual's mental model and that of a referent or expert mental model. Langan-Fox et al. (2001) stated:

The notion that similarity to a referent or expert mental model is associated with superior performance has been consistently supported in a number of domains, which include education (Gillian at al., 1992), electronics (Rowe et al., 1996), computer programming (McDonald et al., 1990), and air traffic control (Vortec et al., 1994). (p.101) 
Langan-Fox et al. (2001) further linked mental models to performance in stating: “A manager's (or expert's) mental model could be considered to represent the 'ideal' model of how the team should be functioning in order for the business unit to be successful" ( $p$. 100).

Additional support for this approach can be found in work done by Acton, Johnson, and Goldsmith (1994) who offered a methodology that looked at the similarity of student and teacher mental models as a reliable predictor of standard measures of classroom performance. Furthermore, studies including Scielzo et al. (2002), Cuevas at al. (2001), and Fiore et al. (2003) all show support for how mental models and knowledge acquisition impact performance. Scielzo et al. (2002) state:

Training systems that enable learners to build an appropriate mental model of the relations between concepts have been shown to encourage the acquisition of knowledge structures more similar to an expert model. Thus, knowledge elicitation techniques can be used to gauge mental model development and as a diagnostic tool to evaluate the manner in which knowledge structure development impacts performance. (p. 566)

Given that support exists linking mental models and performance, the current study investigates the inclusion of mental models as a mediating variable in the relationship between disposition (i.e., Big 5 and GSE) and performance. In line with current research trends aimed at investigating intervening variables in the personality-performance relationship, the hypothesized model included in the current study aims to shed light on one potential indirect, mediating view of relationship between personality and performance.

Considering that sufficient literature exists supporting direct-effect relationships between personality, GSE, and performance, hypothesizing mental model formation as a 
possible mediator is theoretically warranted (Baron \& Kenny, 1986). In this study, it is hypothesized that the relationship between personality (i.e., Big 5 and GSE) and performance is mediated through mental model formation. Consequently, individuals who score high on the Big 5 traits of conscientiousness, emotional stability, extraversion, and emotional stability are hypothesized to be more accurate (when compared to an expert mental model) in their mental model formation, which will lead to higher overall performance. 


\section{Summary and Support of Hypotheses}

Conscientiousness is associated with factors including planfulness and achievement striving (Barrick \& Mount, 1991). Coupled with past research linking conscientiousness to methodic and analytic learning styles (Geisler-Brenstein et al., 1996) and the use of application-directed learning strategies (Basuto et al., 1998), individuals high in conscientiousness are hypothesized to form more accurate mental models of new information through the use of these strategies. In addition, accurate mental model formation is associated with higher overall performance (Langan-Fox et al., 2001) and training performance (Scielzo et al., 2002). Therefore, mental models are hypothesized to mediate the relationship between conscientiousness and performance in that higher levels of the trait conscientiousness will lead to more accurate mental model formation, which will lead to higher performance.

Hypothesis 1. Accurate mental model formation will mediate the relationship between the Big 5 personality trait conscientiousness and performance.

Emotional stability is most associated with a lack of anxiety and overall personal security (Barrick \& Mount, 1991). These relationships along with past research linking neuroticism (low emotional stability) with a lack of cognitive skills (Eysenck, 1967) and poor critical thinking skills, analytical ability, and conceptual understanding (Matthews \& Zeidner, 2004), support the argument that individuals high in emotional stability are more likely to form more accurate mental models through higher amounts of cognitive skills and critical thinking. In addition, given research mentioned above linking mental model formation to performance (Langan-Fox et al., 2001), there is support for the argument 
that higher levels of emotional stability will lead to more accurate mental model formation, which will lead to higher performance.

Hypothesis 2. Accurate mental model formation will mediate the relationship between the Big 5 personality trait emotional stability and performance.

Extraversion is associated with high external-orientation, sociability, and ambition (Barrick \& Mount, 1991). Given the highly social and contextual nature of this trait, individuals high in extraversion are suggested to focus more on external cues in the training context and form mental models in line with that context. Furthermore, individuals higher in extraversion are more likely to be engaged with the instructor and the training; therefore, forming mental models more in common with the instructor. Additionally, research by Basuto et al. (1998) found extraversion to be linked with multiple types of learning strategies including reproduction, application, and meaningdirected learning. These findings support the argument that individuals higher in extraversion are more likely to form common mental models with the instructor and training context as well as engage in several directed learning strategies, which may lead to more accurate mental model formation. Acton et al. (1994) link similarity between a student and teacher's knowledge structure with higher class performance, and LanganFox et al. (2001) found that an expert's mental model does constitute an 'ideal' mental model, this provides support for the hypothesis that higher levels of extraversion will lead to more accurate mental model formation which in turn will lead to higher performance. Hypothesis 3. Accurate mental model formation will mediate the relationship between the Big 5 personality trait extraversion and performance. 
Openness to experience is associated with factors including intellectance, broadmindedness and being open to possibilities (Barrick \& Mount, 1991). Individuals high in openness to experience are more likely to be open-minded and receptive to new ideas. These associations, coupled with research linking openness to experience with deep and elaborative approaches to learning (Geisler-Brenstein et al., 1996) and meaning and directed-learning strategies (Basuto et al., 1998), support the contention that individuals high in openness to experience are more likely to form accurate mental models through higher overall receptiveness to new ideas and the use of elaborative and directed-learning strategies. These findings along with the previously cited research linking mental model similarity and accuracy to performance (Langan-Fox et al., 2001) support the hypothesis that individuals higher in openness to experience are more likely to form accurate mental models which are more likely to lead to higher performance.

Hypothesis 4. Accurate mental model formation will mediate the relationship between the Big 5 personality trait openness to experience and performance.

Impetus for the hypothesized relationship between GSE and mental models can be found in studies that have linked motivational attributes of the individual with the manner and effectiveness in which the individual acquires and/or requests knowledge (Lodewyk \& Winne, 2005; Pintrich \& Degroot, 1990). Support for this relationship can be found in research conducted by Pintrich and Degroot (1990) that linked self-efficacy with the use of more effective tactics and strategies, and in research carried out by Berry (1987), who showed that higher self efficacy lead to greater effectiveness in the cognitive processing of information. Given that mental models constitute cognitive representations of information acquired and/or formed by the individual (Klimoski \& Mohammed, 1994), 
higher levels of GSE are suggested to influence the effectiveness of mental model formation through better cognitive processing and more effective tactics used. This argument coupled with the previously stated relationship between mental models and performance (Langan-Fox et al., 2001) support the hypothesis that individuals higher in general self-efficacy are likely to form more accurate mental models, which is likely to lead to higher performance.

Hypothesis 5. Accurate mental model formation will mediate the relationship between self-efficacy and performance. 


\section{Chapter 3}

\section{Methodology}

\section{Introduction}

This chapter is the description of the methodology used to test the hypothesized model. This discussion proceeds with a description of the 1) characteristics of the site; 2) selection of the sample; 3) procedure to collect data; 4) measurement of the variables; 5) quantitative methods of analyses.

Site

This study was conducted at a large southeastern university. The utilization of this site facilitated access to a suitable and generalizable study population, as well aided in the delivery and capture of study relevant data. On-site technology infrastructure, in terms of internet-based communication, online educational delivery and retrieval platforms, as well as access to the study population made the site well suited for this study.

\section{Sample}

The research sample consisted of 142 undergraduate business students, of which 85 completed the entire assessment. Students were taking part in in-class exercises involving subject matter related to the course in which they were enrolled. Students were enrolled in a first-semester, junior level business course. Data was collected from participants who volunteered for the experiment. Credit was given to those who participated in the study.

\section{Descriptives and Non-Response Analysis}

The total sample included 142 students of which 85 completed the entire study. The sample was made up of 89 males and 53 females with an average age of 23 . Average 
course grade across the entire sample was a B, with an overall sample mean GPA of 3.0. In a non-response analysis, there were significant mean differences in age $(F=6.284, \rho<$ $.05)$, course grade $(F=5.110, \rho<.05)$, and cumulative GPA $(F=10.317, \rho<.05)$ for those who completed the study vs. those who did not. Means were higher in age (24.5 vs. 22.4), course grade (B+ vs. B), and cumulative GPA (3.2 vs. 2.9) for those who did complete the study as opposed to those who did not. Gender breakdown was the same across both samples (i.e., those who completed the study vs. those who did not).

\section{Procedure}

This study used three different surveys/questionnaires, coded data, and knowledge assessments to obtain all the relevant data. The three surveys included a dispositional measure of the Big 5 personality traits; a second 10-item survey aimed at measuring levels of generalized self-efficacy, and a third (Time 1-Time 2) KUMapper survey of individual mental models. The KUMapper survey assessed the relationships between 11 related terms through three rating exercise (i.e., pair-wise ratings, similarity ratings, and spatial mapping), and provided a matrix output for each assessment type. The matrix outputs were analyzed by Pathfinder software to create commonality, similarity, and coherence scores across mental models. These scores were benchmarked against both the instructor's and an expert mental model in creating commonality and similarity scores. Finally, both a content quiz (associated with the subject matter covered in the lecture), and an overall course grade were used as performance measures. Further details associated with each of the surveys can be found in the measurement section included below. 


\section{Methods}

Data was collected across a 6-week time period. All data collection was facilitated through a 'Blackboard' based platform allowing for the online completion of all surveys. All students enrolled in the course had access to Blackboard and accessed all study surveys through this platform. First, the personality survey was made available to the students through Blackboard and students were given one week to complete this survey. Participants were asked to respond to a 50-question survey assessing individual's levels on the Big 5 broad personality traits associated with this study. Within the same survey, participants were also asked 10 questions related to general self-efficacy. In all, the survey contained 60 items that were scaled using Likert-based response sets. The data was collected through online submission of results. Once completed, students were provided access to the initial time-1 mental model assessment.

Upon completion of the Big 5 and GSE survey, participants were asked to take part in the first (Time 1) of two identical term rating exercises using KUMapper (Clariana, 2006) software which assessed students ratings on the similarity of 11 terms associated with the subject of motivation. Students rated the relationship between subject matter terms via 3 separate rating types. The first was a pair-wise rating of all possible terms on a scale of one to nine, the second an abbreviated rating requiring students to choose the term they thought most similar to each other term, and the third, a spatial drag and drop rating where students placed the words in any spatial order they felt appropriate on a blank screen. Once completed separate matrices were created for each of the rating exercises and were later analyzed by Pathfinder network analyses as discussed in the analyses section. 
Upon completion of the initial mental model survey, students took part in a scheduled lecture, which included the subject matter assessed (i.e., motivation). Attendance was recorded, and once the lecture was completed, a second (Time 2) identical KUMapper survey was made available for the students to complete in the exact same fashion and form as the first. Once all three surveys were completed, students were asked to complete a short ten-question quiz on the subject matter of motivation. Finally, final course scores for all participants were collected and analysis of the study variables began.

\section{Measures}

1. Personality: Personality was measured using the IPIP 50 Big 5 factor markers. This measure comes from Goldberg, L. R. (1999), which provided analysis and comparison between some characteristics of the 30 facet scales from the well-known NEO-PI-R (Costa \& McCrae, 1992) and 30 similar constructs measured in the IPIP pool. The average of the Coefficient Alpha values was shown to be higher for the IPIP scales (.80) than for the NEO scales (.75). The average correlation between corresponding scales in the two sets is .73 , which translated into a correlation of .94 when corrected for attenuation. The IPIP Big 5 measure uses a five point Likert-type scale ranging from one (very inaccurate) to five (very accurate).

In the first section of the questionnaire the students were asked to: "Describe how accurately each statement describes you. Describe yourself as you generally are now, not as you wish to be in the future. Describe yourself as you honestly see yourself, in relation to other people you know of the same sex as you, and roughly your same age." Statements in the questionnaire include: "Am the life of the party" (extraversion); "Feel 
little concern for others" (agreeableness); "Am always prepared" (conscientiousness); "Get stressed out easily" (neuroticism); "Have a rich vocabulary" (openness to experience). For the complete list of items used in measuring the Big 5 personality traits, along with item coding to specific traits, please reference appendix A.

2. General Self-Efficacy: General self-efficacy was collected through the use of an online questionnaire containing 10 items on a 4-point Likert-type scale. The ten general selfefficacy questions were derived by Jerusalem and Schwarzer (1986). Responses are made on a 4-point scale, summed up to yield a final composite score with a range from 10 to 40. In samples from 23 nations, Cronbach's alphas ranged from .76 to .90 , with the majority in the high $.80 \mathrm{~s}$. In the first section of the questionnaire the subjects are asked to: Rate themselves on each of the statements from one to four, one being "not at all true" and four being "exactly true." Some of the statements include: "I can always manage to solve difficult problems if I try hard enough," and "If someone opposes me I can find the means and ways to get what I want." Please reference appendix B for all the scale items used in measuring GSE.

3. Mental Models: KUMapper software (Clariana, 2006) was used to assess individual mental models. KUMapper uses three separate assessment types to measure individual mental models. For this study, eleven terms within the domain of motivation were used in all comparisons. These terms included: psychological, safety, social, esteem, selfactualization, equity, inputs, outputs, expectancy, instrumentality, and valence. Through the use of three separate and distinct assessments, participants rated the relationship between the 11 terms in pair-wise, similarity, and mapping exercises. Once completed, participant's mental models were benchmarked against both the instructor's mental 
model and an expert mental model. The instructor's mental model was derived by asking the instructor of the course to complete the same assessment as the students. The instructor's score was then used as the instructor benchmark. The expert mental model was derived by asking two experts in the content area of the terms used (i.e., motivation) to complete the same mental model assessment. Experts' scores were then combined to create and average of their scores which was used as the benchmark for the expert mental model. Experts assessed contained terminal degrees (i.e., $\mathrm{PhD}$ ) in the field ok knowledge (i.e., Industrial and organizational psychology) most associated with terms and theories used in this study, and have published significant work within their respective fields. (See appendix D for print screens of the mental model measure.)

4. Performance: Performance was attained by recording overall course scores and assessing subject matter knowledge through a content quiz. Given that participants in this study had access to the same sets of ancillary and preparatory tools (i.e., text, slides, prep quizzes), and that the procedure and timeline used were the same for all participants; any and all potential exogenous variables were limited to those influenced by dispositional differences in preparation for the exam. Content quizzes associated with domain area covered represented the most valid and immediate feedback regarding performance in the referenced domain area bound by this study.

\section{Analyses}

Given the nature of the data an initial analysis of individual mental models was completed through Pathfinder and KUMapper software. Pathfinder network algorithms (Schvaneveldt, 1990) were used to generate a network representing each participant's (Time 1-Time 2) mental model, along with three measures of coherence, commonality, 
and similarity (discussed below). Experts' and instructor's mental models were assessed in the exact same manner and used as a benchmark to generate commonality and similarity scores across participants.

\section{Pathfinder parameters and coefficients}

Two parameters ( $q$ and $r$ ) had to be determined by the Pathfinder program in order to generate networks. In this study, the parameters used to compute the network were set at $\mathrm{r}=$ infinity and $\mathrm{q}=\mathrm{n}-1$, where $\mathrm{n}$ refers to the number of terms in the data $(\mathrm{n}=11)$. The $\mathrm{r}$ parameter was chosen to match the ordinal properties of the data, and the q parameter was chosen in order to generate the sparsest network possible from the given data. These are the accepted settings for data of the type in this study (Schvaneveldt, 1990). In general, links are made between concepts (nodes) when the similarity between those nodes is greater than or equal to the total similarity of any other path having no more than q links.

The Pathfinder program works by averaging the data of instructors, experts and participant's to obtain consensus networks. These networks can then be compared to each other through the use of both commonality and similarity function in Pathfinder. The commonality between two networks represents the number of links in common across both networks. The similarity between the two networks is computed as the number of links in common divided by uncommon links. (The number of uncommon links is the total number of links in both graphs minus the number of common links.) Two identical networks will yield a similarity of one and two networks that share no links and will have a similarity of 0 . 
The Pathfinder program then determines the probability of obtaining the observed number of links in common or more by chance from the hypergeometric probability distribution. Schvaneveldt (2007) suggests this can be used as a statistical test of similarity; in general you would want there to be less than a .05 probability of the networks sharing these paths by chance in order to say the two networks were statistically similar. This is a test in which the null hypothesis is that the two networks are different. If the probability of sharing links by chance is less than .05 , then the null hypothesis is rejected and the two networks are statistically similar. Lastly, Pathfinder software provided a measure of coherence, which has been used to describe the internal consistency of a subject's knowledge representation. Therefore, coherence could be used as an indirect measure for comparing the knowledge. In essence, the more coherent the knowledge structures, the better representation of that knowledge. The comparison of these two structures to a referent (expert) structure through the use of Pathfinder software generated both a commonality and similarity score, which was be used in a series of multiple regression equations, aimed at testing the direct and mediated relationships in the hypothesized model. Regression analysis in testing direct and mediating relationships

Multiple regression analysis was used to test hypotheses one through five encompassing all hypothesized mediating relationships included in this study. Mediating and moderating techniques in line with Baron and Kenny's (1986) approach (discussed below) were used to test for mediation. Within the framework of this study, conscientiousness, emotional stability, extraversion, openness to experience, and selfefficacy are all hypothesized to have positive direct effect relationships with mental 
model formation. A mediator, by definition, is a factor that, in addition to altering a score on a given measure, in part at least, determines it (Kenny, Korchmaros, \& Bolger, 2003). Taken from Baron and Kenny (1986), "A given variable is said to function as a mediator to the extent that it accounts for the relation between the predictor and the criterion" ( $\mathrm{p}$. 1176). Specific to this study, accuracy in students' mental models was hypothesized to mediate performance. Positing students with more accurate mental models will perform better than those with less accurate mental models.

In the current study, mental model formation was hypothesized to mediate the relationship between dispositional variables (i.e., conscientiousness, extraversion, emotional stability, openness to experience, self-efficacy) and performance. Sticking with Baron and Kenny's (1986) conceptualization, certain conditions must exist for mediation to occur. First, variations in disposition and GSE (as independent variables) must significantly account for variations in the mediating variable, mental model formation. Second variations in the mediating variable, mental model formation, must significantly account for variations in the dependent variable (performance). Mediation is said to occur when a previously significant relationship is no longer significant when controlling for the before-mentioned direct effect relationships between the independent variables (i.e. disposition) and the dependent variable (i.e. performance), and the mediator (i.e. mental model formation) and the dependent variable (i.e. performance). In using regression analysis to test for mediation, "a series of regression models should be estimated" (Baron \& Kenny, 1986, p. 1177). First mental model formation, as a mediator, was regressed on the independent variables of conscientiousness, emotional stability, extraversion, openness to experience, and GSE. Second, performance (as the dependent variable) was 
regressed on the independent variables mentioned above. Third, performance was regressed on both the dispositional traits and mental models. 


\section{Chapter 4}

\section{RESULTS}

Table 7 shows the correlations and reliabilities for all of the study variables. Hypothesized mediation of mental model formation in the personality-performance relationship was not supported. However, significant findings were found in the direct effect relationship between personality and mental model formation, and mental model formation and performance when different benchmarks were used (i.e. instructor vs. expert). See Figure 3 for illustration of the supported relationships.

TABLE 7

\section{CORRELATIONS AMONG HYPOTHESIZED VARIABLES}

\begin{tabular}{lccccccccr}
\hline \multicolumn{1}{c}{ Variable } & 1 & 2 & 3 & 4 & 5 & 6 & 7 & 8 & 9 \\
\hline 1. Extraversion & $(.85)$ & & & & & & & \\
2. Agreeableness & .160 & $(.76)$ & & & & & & \\
3. Conscientiousness & .047 & .146 & $(.82)$ & & & & & \\
4. Emotional Stability & .010 & .068 & $.218^{*}$ & $(.80)$ & & & & \\
5. Openness to Experience & $.402^{* *}$ & $.263^{*}$ & .110 & .139 & $(.73)$ & & & \\
6. Self-Efficacy & $.299^{* *}$ & .026 & .119 & $.280^{* *}$ & $.546^{* *}$ & $(.80)$ & & & \\
7. Commonality & $.244^{*}$ & $.220^{*}$ & -.126 & .058 & .052 & .062 & $(.77)$ & \\
8. Content Quiz & -.060 & .041 & $-.243^{*}$ & .026 & .037 & -.201 & .151 & & \\
9. Final score & -.080 & -.074 & -.023 & -.095 & $-.227^{*}$ & $-.219^{*}$ & -.078 & .098 \\
\hline
\end{tabular}

Findings showed that the Big 5 personality traits Extraversion $(\beta=.060, \rho<.05)$ and Agreeableness $(\beta=.078, \rho<.05)$ did positively and significantly impact commonality with the instructor's mental model, but this did not impact performance. In contrast, when commonality with an expert mental model was present, performance was positively impacted. Commonality with an expert mental model did positively and significantly 
impact performance on both the content quiz $(\beta=2.257, \rho<.05)$ and overall performance in the course $(\beta=7.451, \rho<.05)$. Furthermore, similarity with an expert mental model did positively and significantly impact overall performance in the course ( $\beta$ $=115.729, \rho<.05)$. These findings carry important implications that are discussed below.

\section{FIGURE 3}

\section{SIGNIFICANT DIRECT EFFECTS}

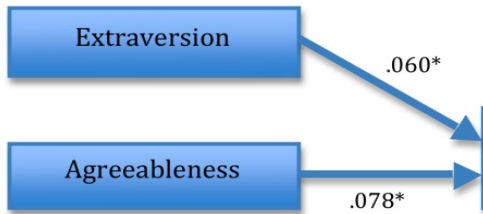

Commonality with

Instructor MM

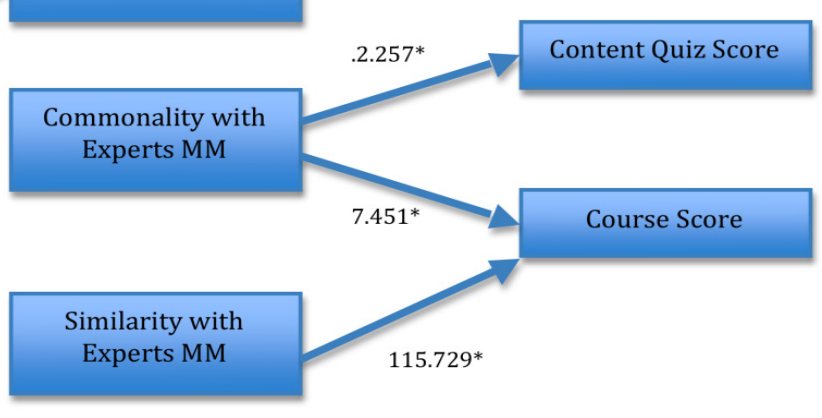

a $\beta$ scores shown

$* \rho<.05$

\section{Tests of Hypotheses 1 through 5: Analyses of Mental Model Formation as a}

\section{Mediator}

Per Hypothesis 1, mental model formation mediates between conscientiousness and performance. In a similar fashion, hypotheses 2 through 4 position mental model formation as a mediator between emotional stability, extraversion, and openness to experience respectively. Lastly, hypothesis 5 posits mental model formation as a mediator for self-efficacy and performance. As discussed previously, Barron and Kenny 
(1986) require four criteria to support mediation: (1) the independent variable (i.e., personality) must significantly relate to the mediator (i.e., mental model formation), (2) the independent variable must significantly relate to the dependent variable (i.e., performance) and, (3) the mediating variable must significantly relate to the dependent variable; while (4) the independent variable no longer relates to the dependent variable.

As shown in Table 8 only extraversion $(\beta=.058, \rho<.05)$ and agreeableness $(\beta=$ $.072, \rho<.05$ ) were found to have a significant, positive relationships with commonality in mental model formation. These were the only significant direct effect in regards to the first criterion for mediation. Further analysis of these relationships (discussed below) showed that the majority of the predictive power in these findings came from the relationship between extraversion, agreeableness and mental model commonality with the instructor. Given the mediating variable included both the instructor's and expert's mental model, significant relationships were lost when testing commonality with the expert's mental model on it's own.

In step 1 of the analysis of content quiz score (Table 8), conscientiousness showed a significant, negative relationship with performance on the content quiz $(\beta=-.777, \rho<$ $.05)$. While this finding supports the second criteria for mediation, it was in the wrong direction. Consequently, all hypothesized mediating relationships (steps 2-6) were not supported. This was due in large part to a lack of significant direct effects and an inability to meet the initial criteria for mediation requiring significant direct relationships between the Big 5 and mental model formation.

Table 9 shows the results for mediation of mental model commonality in the personality-performance relationship, where overall course score was the dependent 
variable. As shown in step 1, analysis of final score only added significant, negative direct effects found between openness to experience $(\beta=-1.829, \rho<.05)$, self-efficacy ( $\beta$ $=-2.623, \rho<.05)$ and performance. Once again, no support was found for mediation in any of the hypothesized relationships due to significant, negative direct effects between personality and performance. It should be noted that the mediating mental model commonality variable used in the hypotheses was a combined mental model score using both the instructor and expert's' mental model. This combined score may have neutralized certain direct effects found when separating the two benchmarks (i.e., instructor vs. expert), specifically those relationships between mental model formation and performance. Further analysis uncovered significant direct effects when distinguishing between mental model benchmarks. Furthermore, analysis of dispositional findings uncovered several possible confounds (discussed below) that may have impacted results. 
TABLE 8

RESULTS OF MEDIATION ANALYSIS FOR CONTENT QUIZ PERFORMANCE,

\begin{tabular}{lccc}
\hline \multicolumn{1}{c}{ Step and Predictors } & Estimate & $\mathbf{s . e}$ & $\sim \mathbf{R}^{2}$ \\
\hline MV. Mental Model Commonality & & & \\
1. Conscientiousness & -.035 & .031 & .016 \\
Emotional Stability & .015 & .028 & .003 \\
Extraversion & $.058^{*}$ & .026 & .059 \\
Openness to Experience & .017 & .036 & .003 \\
Self-Efficacy & .031 & .054 & .004 \\
Agreeableness & $.072^{*}$ & .035 & .049 \\
DV. Quiz Score & & & \\
1. Conscientiousness & & & \\
Emotional Stability & $-.777^{*}$ & .351 & .059 \\
Extraversion & .073 & .318 & .001 \\
Openness to Experience & -.165 & .314 & .004 \\
Self-Efficacy & .139 & .423 & .001 \\
Agreeableness & -1.124 & .621 & .040 \\
2. Conscientiousness & .151 & .414 & .002 \\
Mental Model Commonality & $-.714^{*}$ & .357 & \\
3. Emotional Stability & 1.291 & 1.281 & .012 \\
Mental Model Commonality & .040 & .318 & \\
4. Extraversion & 1.727 & 1.298 & .022 \\
Mental Model Commonality & -.262 & .318 & \\
5. Openness to Experience & 1.961 & 1.316 & .028 \\
Mental Model Commonality & .089 & .422 & \\
6. Self-Efficacy & 1.715 & 1.299 & .022 \\
Mental Model Commonality & -1.222 & .619 & \\
7. Agreeableness & 1.992 & 1.269 & .030 \\
Mental Model Commonality & .020 & .424 & \\
\hline n =85 individuals & 1.724 & 1.333 & .021 \\
* 0 < .05 & & & \\
& & &
\end{tabular}


TABLE 9

RESULTS OF MEDIATION ANALYSIS FOR FINAL SCORE PERFORMANCE ${ }^{\mathrm{a}, \mathrm{b}}$

\begin{tabular}{|c|c|c|c|}
\hline Step and Predictors & Estimate & s.e & $\sim R^{2}$ \\
\hline \multicolumn{4}{|l|}{ MV. Mental Model Commonality } \\
\hline 1. Conscientiousness & -.035 & 031 & .016 \\
\hline Emotional Stability & .015 & .028 & .003 \\
\hline Extraversion & $.058^{*}$ & .026 & .059 \\
\hline Openness to Experience & .017 & .036 & .003 \\
\hline Self-Efficacy & .031 & .054 & .004 \\
\hline Agreeableness & $.072^{*}$ & .035 & .049 \\
\hline \multicolumn{4}{|l|}{ DV. Final Score } \\
\hline 1. Conscientiousness & -159 & .755 & .001 \\
\hline Emotional Stability & -.581 & .671 & .009 \\
\hline Extraversion & -.465 & .640 & .006 \\
\hline Openness to Experience & $-1.829^{*}$ & .865 & .052 \\
\hline Self-Efficacy & $-2.623^{\star}$ & 1.289 & .048 \\
\hline Agreeableness & -.585 & .871 & .005 \\
\hline 2. Conscientiousness & -.263 & .765 & \\
\hline Mental Model Commonality & -1.996 & 2.691 & .007 \\
\hline 3. Emotional Stability & -.557 & .674 & \\
\hline $\begin{array}{l}\text { Mental Model Commonality } \\
\text { 4 Fxtraversion }\end{array}$ & $\begin{array}{l}-1.769 \\
-377\end{array}$ & $\begin{array}{c}2.660 \\
662\end{array}$ & .005 \\
\hline 4. Extraversion & -.377 & & \\
\hline Mental Model Commonality & -1.508 & 2.743 & .004 \\
\hline 5. Openness to Experience & $-1.803^{*}$ & .869 & \\
\hline Mental Model Commonality & -1.626 & 2.603 & .005 \\
\hline 6. Self-Efficacy & -2.573 & 1.297 & \\
\hline Mental Model Commonality & -1.550 & 2.611 & .004 \\
\hline 7. Agreeableness & -.472 & .897 & \\
\hline Mental Model Commonality & -1.570 & 2.729 & .004 \\
\hline
\end{tabular}


In an attempt to better understand some of the negative direct effect relationships between personality and performance, several analyses were run to test dispositional scores. First, a chi-square test of fit showed significant differences from expected values on all the personality traits measured. The Big 5 measure used in this study assessed the Big 5 traits on 10 item scales ranging from a low score of 10 to a high score of 50 . Scores in this study were asymptomatic of this range and therefore showed poor fit. Causes for this are discussed below and include inflated scores and sample specific confounds. Furthermore, descriptive statistics showed highly negatively skewed scores on the personality traits measured illustrating a lack of representation of low scores across the scale. Tables 10 and 11 report these results. Implications of this are discussed below.

TABLE 10

Chi-Square test of Personality Scale

\begin{tabular}{lrrrrrr}
\hline & Extraversion & Agreeableness & Conscientiousness & $\begin{array}{c}\text { Emotional } \\
\text { Stability }\end{array}$ & $\begin{array}{c}\text { Openness to } \\
\text { Experience }\end{array}$ & $\begin{array}{c}\text { Self- } \\
\text { Efficacy }\end{array}$ \\
\hline Chi-Square & $70.800^{\mathrm{a}}$ & $146.047^{\mathrm{a}}$ & $82.376^{\mathrm{a}}$ & $86.235^{\mathrm{a}}$ & $141.224^{\mathrm{a}}$ & $207.788^{\mathrm{a}}$ \\
df & 40 & 40 & 40 & 40 & 40 & 40 \\
Asymp. Sig. & .002 & .000 & .000 & .000 & .000 & .000 \\
\hline
\end{tabular}

TABLE 11

Descriptive Statistics and Skewness of Personality Variables

\begin{tabular}{lccccc}
\hline \multicolumn{1}{c}{ Variable } & Minimum & Maximum & Mean & Std. Deviation & Skewness \\
\hline Extraversion & 13 & 49 & 33.80 & 7.732 & -.243 \\
Agreeableness & 18 & 50 & 39.36 & 5.654 & -.934 \\
Conscientiousness & 24 & 50 & 38.51 & 6.606 & -.118 \\
Emotional Stability & 16 & 48 & 34.13 & 7.392 & -.319 \\
Openness to Experience & 24 & 50 & 38.26 & 5.572 & -.273 \\
Self-Efficacy & 24 & 40 & 33.68 & 3.736 & -.388 \\
\hline
\end{tabular}


Second, in an analysis of personality scores between those who completed the entire measure $(n=85)$ and those who did not $(n=52)$, significant differences in mean scores on the Big 5 traits, conscientiousness $(F=7.287, \rho<.05)$ and emotional stability $(F=6.077, \rho<.05)$ were present. In other words, those who completed the entire measure did have significantly higher scores on the traits of conscientiousness and emotional stability then those who did not. This representation of high scores for those who completed the entire measure may have impacted results. Furthermore, while negative relationship between personality and performance were found in the study, individuals who actually self-selected to complete the study were higher in the traits of conscientiousness and emotional stability. It is possible that actual selection into the study was an indirect proxy of performance where higher levels of conscientiousness and emotional stability predicted those who did select to take the study.

Third, an analysis of gender showed significant differences in variance across five of the six dispositional traits (Table 12). Considering the whole sample ( $\mathrm{n}=142)$, mean scores for males were significantly higher then female scores on the traits of extraversion, agreeableness, emotional stability, openness to experience, and self-efficacy. Given these findings, gender was analyzed as a possible predictor of mental model formation. Results from the analysis showed no relationship between gender and mental model commonality with the instructor or expert. However, future analysis of the role of gender and/or gender match may provide further insight related to the findings of this study. 
TABLE 12

ANALYSIS OF VARIANCE OF PERSONALITY SCORES BY GENDER

\begin{tabular}{lcccc}
\hline \multicolumn{1}{c}{ Variable } & Males & Females & Total & Sig. \\
\hline Extraversion & 35.59 & 32.98 & 34.56 & .037 \\
Agreeableness & 38.32 & 40.53 & 39.19 & .024 \\
Conscientiousness & 37.29 & 37.21 & 37.26 & .949 \\
Emotional Stability & 34.76 & 30.12 & 32.93 & .000 \\
Openness to Experience & 38.91 & 36.98 & 38.15 & .033 \\
Self-Efficacy & 34.22 & 32.35 & 33.48 & .004 \\
\hline
\end{tabular}

\section{Supplementary Analyses}

Given the possibility of students' overall classroom achievement confounding the findings of this study, supplementary analysis was conducted in order to control for overall students' success in the classroom via their cumulative GPA. Table 13 provides results of the analysis. Analysis showed that even when controlling for overall classroom ability (as measured through the student's cumulative GPA), commonality with the expert's mental model did predict success on both the content quiz and final course score. In essence, beyond overall student ability to do well in classroom settings, commonality with an expert mental model did predict performance in the class. This is a critical consideration in that mental models do predict performance above and beyond ability. While past performance in classroom settings is predictive of future performance, students' ability to form accurate mental models is uniquely predictive of performance. Furthermore, extraversion and agreeableness did predict mental model commonality with the instructor even when controlling for cumulative GPA. Again, despite students overall ability to do well in courses, extraversion and agreeableness still predict mental model commonality with the instructor. Consequently, beyond ability, agreeable extraverts do 
form more common mental models with the course instructor. This added analysis further strengthens the findings of this study in that mental models are unique and independent predictor of performance.

TABLE 13

\section{Analysis of Significant Findings controlling for Cumulative GPA}

\begin{tabular}{|c|c|c|c|}
\hline Step and Predictors & Estimate & s.e & $\sim R^{2}$ \\
\hline \multicolumn{4}{|c|}{ Mental Model Commonality Instructor } \\
\hline 1. Extraversion & $.060 *$ & .027 & .056 \\
\hline 2. CUM GPA & -.382 & .402 & .011 \\
\hline Extraversion & $.059 *$ & .027 & .067 \\
\hline 1. Agreeableness & $.078 *$ & .037 & .053 \\
\hline 2. CUM GPA & -.310 & .406 & .011 \\
\hline Agreeableness & $.075^{*}$ & .037 & .059 \\
\hline \multicolumn{4}{|l|}{ Content Quiz } \\
\hline 1. Expert Commonality (trad) & $2.257^{*}$ & 1.125 & .049 \\
\hline 2. CUM GPA & .597 & 4.512 & .000 \\
\hline Expert Commonality (trad) & $2.282^{*}$ & 1.148 & .049 \\
\hline \multicolumn{4}{|l|}{ Final Score } \\
\hline 1. Expert Commonality (map) & $7.451^{*}$ & 3.038 & .068 \\
\hline 2. CUM GPA & $56.927 * *$ & 7.281 & .420 \\
\hline Expert Commonality (map) & $6.352 * *$ & 2.312 & .469 \\
\hline 1. Expert Similarity (map) & $115.729 * *$ & .49 .047 & .064 \\
\hline 2. CUM GPA & $57.045^{* *}$ & 7.299 & .420 \\
\hline Expert Similarity (map) & $99.202 * *$ & 37.321 & .466 \\
\hline
\end{tabular}




\section{Chapter 5}

\section{DISCUSSION}

This study adds a unique view to the existing literature on the relationship between personality and performance. Few studies, if any, have investigated mental models as a potential mediator of the relationship between dispositional personality traits and performance outcomes. As previously discussed, the personality- performance relationship has come under debate given the complexity of findings for both direct and indirect relationships between these constructs (Hurtz \& Donovan, 2000; McCrae \& Costa, 1987; Morgeson et al., 2007; Ones, Dilchert, Viswesvaran, \& Judge, 2007; Tett \& Christiansen, 2007). Calls for research have been made to investigate potential indirect, such as mediating relationships between personality and performance (Hurtz \& Donovan, 2007 and Westerman \& Simmons, 2007). The findings of the current study answer this call and extend our understanding of the personality-performance relationship by adding a unique view of how personality potentially influences performance.

The aim of this study was to contribute to the literature regarding potential indirect, mediating variables for the personality-performance relationship. In particular, mental models were investigated as a potential mediating construct to explain the manner in which personality impacts performance. While full mediation was not found in the current study, significant and important direct effects were revealed that could aid the advancement of the line of research on personality and performance. Specifically, the current study has found that extraversion and agreeableness did impact mental model formation, but that mental model formation only impacted performance when accurate mental models were formed. 


\section{Implications}

Findings from the current study show that higher levels of extraversion and agreeableness did impact individual mental model commonality with the instructor. These findings extend previous research validating mediating mechanisms in the personality-performance relationship. In line with past research showing task performance (Gellatly, 1996), job autonomy (Gellatly \& Irving, 2001), and work environment (Westerman \& Simmons, 2007) as just a few of the valid mediators for the effect personality has on performance, this study explores mental model formation as a unique and new mediating mechanism impacting performance. If the type of personality an individual has influences the manner in which he/she forms mental models, then implications in the fields of knowledge transfer, training, and management become apparent. All types of organizations use a host of knowledge transfer tools to ensure that their human capital is well trained and informed. Whether through on-the-job training, apprenticeship, supervisor-subordinate interaction, or mentoring, knowledge, skills and abilities (KSAs) are constantly transferred from one person to another. Future research may benefit from investigating the impact of differences in personality on the way in which individuals retain and organize information.

Extraversion has long been associated with overall sociability, assertiveness, and talkativeness (Digman, 1990). As is the case in any organizational knowledge transfer initiative, effective communication is critical to effective knowledge transfer. If highly extraverted individuals are more likely to communicate and socialize with others, then these individuals may be more influenced by interpersonal and social cues in their formation of mental models. This provides support for the finding of this study that 
individuals high in extraversion did form more common mental models with the instructor. In this study, those individuals who were higher in extraversion may have been more likely to engage in social interaction and communication with the instructor, thereby forming more common mental models with the instructor. Future research may benefit from investigating the potential role of social and contextual cues on the effectiveness of training outcomes.

In addition, extraverted individuals are more likely to have a desire to work with others and feel more confident in that capacity (Barrick, Stewart, Neubert, \& Mount (1998; Thoms, Moore, \& Scott, 1996). If individuals higher in extraversion felt more efficacious in their capacity to engage with the instructor, then these individuals would be more likely to form common mental models through that engagement. In contrast, individuals lower in extraversion would not communicate with the instructor or engage in class lectures as intensively and would not be likely to share common mental models with the instructor. Additionally, lower levels of self-efficacy (in a social environment) potentially associated with lower levels of extraversion might have limited these individuals' involvement in the lecture, as they would not have felt comfortable within that role. It may be possible that extraverts facilitate and, to a certain extent, dominate the training environment and, therefore, limit the learning of others. Future research may investigate the overall effect of higher levels of extraversion on the training environment. Additionally, future research may further study whether extraversion is a necessary prerequisite of effective learning or not.

Furthermore, individuals higher in extraversion are more likely to show positive affectivity, which has been shown to facilitate positive and cooperative interactions with 
others (Hogan \& Holland, 2003; LePine \& Van Dyne, 2001). If highly extraverted individuals are more likely to be positive and cooperative with the instructor, then initial formation of common mental models may be bolstered. On the contrary, individuals with neutral or negative affectivity and cooperation towards the lecture and instructor are likely to not be as engaged and, therefore, share less common mental models with the instructor. Overall, the findings in the current study are in line with previous research (Hogan \& Holland, 2003; LePine \& Van Dyne, 2001) in that individuals higher in extraversion did form more common mental models with the instructor whereas introverts did not. One potential area of future research is whether positive affectivity is distinguishable from extraversion with regards to learning, and if so through which mechanisms.

Additionally, findings from the current study showed that agreeableness positively impacted mental model commonality with the instructor. Agreeableness is known to encompass cooperativeness and flexibility (Barrick \& Mount, 1991); therefore, individuals higher in agreeableness would seem more likely to accept or entertain the ideas of others. In the current study, individuals higher in agreeableness might have been more open and adaptive to the lecture and to the instructor and, therefore, have been more likely to form common mental models with the instructor. Future research may consider examining whether more agreeable individuals do actually perform better then less agreeable individuals and in which kinds of contexts (e.g., supervisory-subordinate relationship, apprenticeship, on-the-job training, or mentoring).

Of critical importance here is the nature of the KSAs that are transferred. Findings from the current study point to the potential problem of inaccurate mental model 
formation due to supervisors'/trainers'/managers' inaccurate understanding of the KSAs being transferred. Since commonality with the instructor did not lead to higher performance, considerations of the content expertise of the manager or trainer are critical. Of particular interest here is the notion that if managers and trainers do not encompass the ideal mental model for the area of expertise, performance may suffer. Organizations may benefit from considering the level of trainers'/managers' expertise before allowing any type of knowledge transfer (e.g., KSAs, experience) to others.

The reason why certain traits did impact mental model commonality with the instructor, but not with the expert mental model, point to the social components of the traits themselves. As discussed earlier, the lecture constituted a highly social, cooperative context in which students were expected to participate. Higher levels of participation by those higher in extraversion and agreeableness might have lead to more common mental models with the instructor. Since the expert mental model was not explicitly communicated or provided to the students via the instructor or lecture, the social components of extraversion and agreeableness did not impact commonality with the expert's mental model. This is critically important given that in the current study commonality with the expert's mental model did impact performance. It is possible that the Big 5 personality traits, conscientiousness and openness to experience, that do not encompass a social component could have minimized mental model formation with the instructor. Highly conscientious individuals tend to exhibit planfulness (Barrick, Mount, \& Judge, 2001) and order and may not be as open to social discussions and lectures on the subject matter. Furthermore, openness to experience is associated with intellectance (Barrick \& Mount, 1991), which could have limited mental model formation with the 
instructor vis-à-vis previously formed mental models by those individuals higher in intellectance.

Lastly, causes as to why commonality with the instructor did not lead to higher performance may include, 1) a limited understanding by the instructor of the subject matter lectured, 2) a divergent view of the subject matter from those of the experts. Since the performance measures used in this study (i.e., content quiz and course exams) incorporated content questions taken from a textbook's bank of questions, it is possible that the mental model of the instructor was not in congruence with the 'ideal' mental model measured by the questions. Oftentimes, there is a divergence in the views of an instructor and other ancillary materials used to communicate the subject matter to students, which may limit accurate mental model formation. In the case of the current study, performance was assessed via generalized questions created to assess textbook knowledge, and, therefore, did not necessarily match the mental models of the instructor. It is possible that had the instructor written the questions used in both the content quiz and course exams, mental model commonality with the instructor could have lead to performance. This contention could be a slippery slope in that one must question what constitutes an accurate mental model. For the purposes of this study, experts in the subject matter assessed encompassed a more ideal and accurate mental model then the instructor.

If managers, trainers, and bosses do encompass the ideal mental model of a certain set of KSAs, then transfer of those KSAs will lead to higher performance. However, it is possible for inaccurate mental models to override accurate mental models if instructors, trainers, and managers possess inaccurate mental models. Furthermore, 
highly extroverted and agreeable individuals are more susceptible to inaccurate mental model formation given their more frequent interactions with others. If organizations can control for and manipulate knowledge transfer to fit ideal mental models of a subject area, then performance should be bolstered. Impetus on ensuring the proper organizational environment for accurate mental model formation is critical. Above and beyond the manager or trainer, multiple other contextual factors (e.g., orientation, employee handbooks, informal training) could aid in ensuring accurate mental model formation by organizational members.

In the current study, negative, direct relationships have been investigated among a number of personality traits and performance outcomes. As indicated in the results section of the current study, supplementary analyses were also conducted to identify possible confounds that would potentially lead to negative relationships among personality traits and performance outcomes. These analyses uncovered several possible confounds that need to be considered. For example, the Big 5 scores in the current study were all elevated showing strong negative skews with relatively few low scores across the personality traits. In other words, individuals inflated self-reported scores on all of the measures of personality. Impression management (i.e., faking), and self-presentation tactics may be a few of the potential causes for this inflation and are discussed below.

As employees look to advance and promote within their organization, and receive favorable evaluations from their supervisors and other employees, they aim to present themselves in the most positive light possible in order to ensure positive organizational outcomes. These self-presentation tactics (e.g., impression management) are often employed to satisfy the perceptions of trainers, supervisors, managers, executives, and 
other employees. Impression management is defined as an individual's wish to be viewed in a positive light by others and behaving in such a way to maximize the chances of achieving this end (Baumister, 1982; Schlenker, 1980). In work done by Hogan, Hogan, and Roberts (1996), impression management was shown to be a possible predictor of job performance adding testament to the importance of such behaviors in organizational settings. In arguing for a broad approach to the conceptualization of job performance, these authors conceded that multiple predictors of performance may exist, one of which included impression management strategies. Furthermore, more contemporary views of job performance have come to recognize the multi-dimensional nature of the personality construct and include impression management as a strategy that does predict certain types of job performance (Viswesvaran, Ones, \& Hough, 2001). It is very likely that participants in the current study perceived the experiment as a way to put forth a positive impression with their instructor much in the same way employees may take different opportunities to form positive impressions with their supervisors.

Further evidence of these self-presentation tactics can be found in a study by Paulhus, Bruce, and Trapnell (1995), where the Big 5 personality traits were measured based on different types of self-presentation strategies (i.e., faking worst to faking best). The results of their study confirmed previous findings showing a decreased utility of personality measures under self-presentation conditions. In other words, individuals tended to inflate the positivity component of their scores, thereby reducing the validity of their overall scores. In their study, the Big 5 trait of conscientiousness was the trait most impacted by self-presentation strategies. This is an important finding as 
conscientiousness scores were highly elevated in the current study as well, presumably due to self-presentation and impression management strategies.

In the same study by Paulhus et al. (1995), agreeableness was also highly impacted by faking although ceiling effects did limit high scores. The researchers cited concerns of participants seeming too compliant as a possible cause for the ceiling effects. Without taking too far of a leap, one could imagine the negative light attributed to those who are the "teacher's pet" or "the boss's favorite". In the end, the researchers' findings showed evidence that virtually any self-reporting inventory that includes multiple forms of positivity will suffer from self-presentation strategies. In the current study, it is possible that only those individuals concerned with casting a positive impression actually put forth the effort to complete the entire measure. Other individuals, less interested in impression management and self-presentation, may have opted to not put forth the effort in completing the measure. Consequently, some individuals saw the study as an opportunity to cast a positive light on themselves, and behaved in such a way as to achieve a positive impression. This faking by individuals of their scores on the Big 5 might have limited variance in the independent variable, thereby impacting the findings in the current study.

One other way to interpret the results of the current study is that those participants who did complete the entire study were those individuals that legitimately scored higher on the traits of conscientiousness and emotional stability. In other words, while negative relationships were found between conscientiousness and performance within the current study, scores on the Big 5 traits of conscientiousness and emotional stability were higher for those individuals who self-selected to complete the entire study as opposed to those 
individuals who chose not to complete the entire study. In essence, initial performance (i.e., actually completing the entire study) was much higher for those higher in conscientiousness and emotional stability. This may have restricted the range of scores within the study and limited potential findings.

\section{Limitations and Future Research}

In contrast to studies that have tested the personality-performance relationship in organizational settings, the current study used a student sample. As was discussed in the implications section above, some confounds may have surfaced as a result of utilizing such a sample. Future research may benefit from extending the findings of the current study to organizational settings in order to confirm whether the implications stated earlier do generalize across different sample populations. Accessing a more generalized sample of the population may mitigate the potential range restriction in personality scores found in the current study. The sample used in the current study (i.e., undergraduate students taking their first business course) may have generated elevated scores on many of the personality measures through sample specific scores since the participants were undergraduate business students, and because of the self-report bias given the elevated scores. This does not mean that similar scores and self-presentation tactics would not be found in organizational settings; however, future studies would benefit from ruling out this possibility. Furthermore, a non-response analysis yielded significant differences in age, grade, and cumulative GPA for those participants who completed the study as opposed to those who did not. While supplementary analyses validated the primary findings in the current study when controlling for cumulative GPA, future research could 
benefit from investigating whether age and ability would impact the findings such as those found in the current study.

Another limitation of the current study is that participants may have embellished their scores on the personality measures to favor what was perceived as 'good scores' on the measures of the Big 5 and general self-efficacy. While self-presentation tactics and impression management strategies may still exist in organizations, testing in an organizational environment would add face validity to the current findings. Yet another limitation is that participants who completed all parts of the experiment (i.e., personality measures, mental model time 1 , mental model time 2 , and the content quiz) scored significantly higher on the traits of conscientiousness and emotional stability then those who did not. Future research may consider studying a wide range of scores for conscientiousness and emotional stability in order to ensure proper representation of these traits in the study sample. In the current study, it seems that higher levels of conscientiousness and emotional stability did suggest which individuals completed the entire study and which individuals did not. This completion could be considered an indirect measure of performance and may warrant further investigation.

Lastly, performance measures used in the current study incorporated quiz and test questions derived from the publisher's test bank associated with the textbook used in the course. While commonality with the instructor's mental model did not lead to higher performance in the current study, this may have been due to the nature of the questions used in the assessment of students' performance (i.e., the textbook's test bank questions). If the instructor had generated the questions used in assessing performance himself or herself, it is possible that mental model commonality with the instructor may have lead to 
higher levels of performance. However, at the same time, one should be cautious in using questions generated by the instructor of the course given that the instructor's mental model may not represent the 'ideal' mental model of the subject matter. In essence, would performance based on an instructor's understanding of a specific subject matter constitute true performance? A major critique one could see in this approach would be whether the instructor has an ideal or accurate understanding of the material. Based on this critique, the findings of the current study offer greater distinction by using multiple benchmarks showing expert mental models to be more in line with ideal mental models and, therefore, performance.

\section{Conclusion}

Further research is warranted to truly understand the role personality plays in individual performance. As has been the case for the last century evolving considerations and investigations of the personality-performance relationship have looked at novel and unique ways to better explain how personality impacts performance. The findings of the current study add to this line of research by exploring mental models as a potential mediating variable in the personality-performance relationship. Findings from the current study point to the important role personality plays in the manner in which individuals organize information (i.e., mental model formation). Furthermore, the findings of the current study suggest that the manner in which information is organized does impact performance. Future research may continue to investigate the role of mental model formation in potentially explaining the personality-performance relationship. Further research investigating mental model formation may shed light on why individuals with 
certain personality types (e.g., extraversion, agreeableness, conscientiousness) would potentially perform at higher levels than others. 


\section{LIST OF REFERENCES}

Abelson, R. P. (1976). Script processing in attitude formation and decision-making. Cognition and social behavior. Oxford, England: Lawrence Erlbaum.

Acton, W. H., Johnson, P.J., \& Goldsmith, T. E. (1994). Structural knowledge assessment: Comparison of referent structures. Journal of Educational Psychology, 86(2), 303-311.

Anderson, J. R. (1980). Concepts, propositions, and schemata: What are the cognitive units? Nebraska Symposium on Motivation, 28, 121-162.

Anderson, G., \& Viswesvaran, C. (1998). An update of the validity of personality scales in personnel selection: A meta-analysis of studies published after 1992. Paper presented at the $13^{\text {th }}$ Annual Conference of the Society of Industrial and Organizational Psychology, Dallas.

Axelrod, R. (1976). Structure of decision: The cognitive maps of political elites. Princeton, NJ: Princeton University Press.

Bandura, A. (1977). Self-efficacy: Toward a unifying theory of behavioral change. Psychological Review, 84(2), 191-215.

Bandura, A. (1982). Self-efficacy mechanism in human agency. American Psychologist, $37(2), 122-147$.

Bandura, A. (1993). Perceived self-efficacy in cognitive development and functioning. Educational Psychologist, 28, 117-148.

Bandura, A., \& Locke, E. A. (2003). Negative self-efficacy and goal effects revisited. Journal of Applied Psychology, 88(1), 87-99.

Bandura, A., \& Schunk, D. H. (1981). Cultivating competence, self- efficacy, and intrinsic interest through proximal self-regulation. Journal of Personality and Social Psychology, 41, 586 -598.

Bandura, A., \& Wood R. (1989). Social cognitive theory of organizational management. Academy of Management Review, 14(3), 361-384.

Baron, R. M., \& Kenny, D A. (1986). The moderator-mediator variable distinction in social psychological research: Conceptual, Strategic, and Statistical considerations. Journal of Personality and Social Psychology, 51(6), 1173-1182.

Barrick, M. R., \& Mount, M. K. (1991). The Big Five personality dimensions and job performance: A meta-analysis, Personnel Psychology, 44(1), 1-26. 
Barrick, M. R., \& Mount M. K. (1993). Autonomy as a moderator of the relationship between the big five personality dimensions and performance. Journal of Applied Psychology, 78(11), 111-118.

Barrick, M. R., \& Mount, M. K. (1998). Five reasons why the "Big-five" article has been frequently cited. Personnel Psychology, 51, 849-857.

Barrick, M. R., Mount, M.K., \& Judge, T. A. (2001). Personality and performance at the beginning of the new millennium: What do we know and where do we go next?

Personality and Performance, 9(1/2), 9-30.

Barrick, M. R., Mount, M. K., \& Strauss, J. P. (1993). Conscientiousness and performance of sales representatives: Test of the mediating effects of goal setting. Journal of Applied Psychology, 78(5), 715-722.

Barrick, M. R., Stewart, G. L., Neubert, M. J., \& Mount, M. K. (1998). Relating member ability and personality to work-team processes and team effectiveness. Journal of Applied Psychology, 83, 377-391.

Basuto, V. V., Prins, F. J., Elshout, J. J, \& Hamaker C. (1998). The relation between learning styles, the Big 5 personality traits and achievement motivation in higher education, Personality and Individual Differences, 26(1), 129-140.

Baumister, R. F. (1982). Self-esteem, self-presentation, and future interaction: A dilemma of reputation. Journal of Personality, 50(1), 29-47.

Beaty, J. C., Cleveland, J. N., \& Murphy, K. R. (2001). The relation between personality and contextual performance in "strong" versus "weak" situations. Human Performance, 14(2), 125-148.

Behling, O. (1998). Employee Selection: Will intelligence and conscientiousness do the job? The Academy of Management Executive, 12(1), 77-86.

Berry, J. M. (1987, August). A self-efficacy model of memory performance. Paper presented at the 95th Annual Convention of the American Psychological Association, New York, NY.

Bidjerano, T., \& Yun Dai D. (2007). The relationship between the big-five model of personality and self-regulated learning strategies. Learning and Individual Differences, 17(1), 69-81.

Bosscher, R. J., \& Smit, J. H. (1998). Confirmatory factor analysis of the general selfefficacy scale. Behaviour Research and Therapy, 36(3), 339-343. 
Chen, G., Casper, W. J., \& Cortina, J. M. (2001). The roles of self-efficacy and task complexity in the relationships among cognitive ability, conscientiousness, and work-related performance: A meta-analytic examination. Human Factors, 14(3), 209-230.

Chen, G, Gully, S. M., \& Eden, D. (2004). General self-efficacy and self-esteem: Toward theoretical and empirical distinction between correlated self-evaluations. Journal of Organizational Behavior, 25(3), 375-395.

Clariana, R. B. (2006). A comparison of pair-wise, list-wise, and clustering approaches for eliciting structural knowledge. International Journal of Instructional Media, 36(3) (in press).

Costa, P. T., \& McCrae, R. R. (1988). Personality in adulthood: A six-year longitudinal study of self-reports and spouse ratings on the NEO Personality Inventory. Journal of Personality and Social Psychology, 54(5), 853-863.

Costa, P. T., \& McCrae, R. R. (1992). Four ways five factors are basic. Personality and Individual Differences, 13(6), 653-665.

Cuevas, H. M., Fiore, S. M., \& Oser R. L. (2001). The facilitative effects of diagrams on scaffolding knowledge acquisition and metacognition in low verbal ability learners. Proceedings of the $45^{\text {th }}$ Annual Meeting of the Human Factors and Ergonomics Society, 936-940. Santa Monica, CA: HFES

Daniels, K., de Chernatony, L., \& Johnson G. (1995). Validating a method for mapping managers' mental models of competitive industry structures. Human Relations, 48(9), 975-991.

Digman, J. M. (1990). Personality structure: emergence of the five-factor model. Annual Review of Psychology, 41, 417-440

Eden, D. (1998). Pygmalion, goal setting, and expectancy: Compatible ways to raise productivity. Academy of Management Review, 13, 639-652.

Eden, D., \& Aviram, A. (1993). Self-efficacy training to speed reemployment: Helping people to help themselves. Journal of Applied Psychology, 78(33), 352-360.

Eden, D., \& Zuk, Y. (1995). Seasickness as a self-fulfilling prophecy: Raising selfefficacy to boost performance at sea. Journal of Applied Psychology, 80(55), 625635.

Eysenck, H. J. (1967). The Biological Basis of Personality. New Brunswick, NJ: Transaction Publishers. 
Fiore, S. M., Cuevas, H. M., \& Oser, R. L. (2003). A picture is worth a thousand connections: The facilitative effects of diagrams on task performance and mental model development. Computers in Human Behavior, 19, 185-199.

Fiske, S. E., \& Taylor S. E. (1991) Social Cognition. New York, NY: McGraw Hill, Inc.

Ford, J. D., \& Hegarty, W. H. (1984). Decisions maker's beliefs about the causes and effects of structure: An exploratory study. Academy of Management Journal, 27(2), 271-291.

Geisler-Brenstein, E., Schmeck, R. R., \& Hetherington, J. (1996). An individual difference perspective on student diversity. Higher Education, 31(1), 73-96.

Gellatly, I. R. (1996). Conscientiousness and task performance: Test of a cognitive process model. Journal of Applied Psychology, 81(55), 474-482.

Gellatly, I. R., \& Irving, P. G. (2001) Personality, autonomy, and contextual performance of managers. Human Performance, 14(3), 231-245.

Gillian, D. J., Breddin, S. D., \& Cooke N. J. (1992). Network multidimensional representations of the declarative knowledge of human computer interface design experts. International Journal of Man Machine Studies, 36(4) 587-615.

Gist, M. E. (1989). The influence of training method on self-efficacy and idea generation among managers. Personnel Psychology, 42(4), 787-805.

Gist, M. E., \& Mitchell, T. R. (1992). Self-efficacy: A theoretical analysis of its determinants and malleability. Academy of Management Review, 17(2), 183-211.

Goldberg, L. R. (1990). An alternative "description of personality": the big-five factor structure. Journal of Personality and Social Psychology. 59, 1216-1229.

Goldberg, L. R. (1999). A broad-bandwidth, public domain, personality inventory measuring the lower-level facets of several five-factor models. Personality Psychology in Europe, 7, 7-28.

Guion, R. M., \& Gottier, R. F. (1965). Validity of personality measures in personnel selection. Personnel Psychology, 18(2), 135-164.

Hayes, R. H. \& Clark, K. B. (1985). Explaining observed productivity differentials between plants: Implications for operations research. Interfaces, 15, 3-14.

Hill, T., Smith, N. D., \& Mann, M. F. (1987). Role of efficacy in predicting the decision to use advanced technologies: The case of computers. Journal of Applied Psychology, 72(2), 307-313. 
Hochwater, W. A., Witt, L. A., \& Kacmar, K. M. (2000) Perceptions of organizational politics as a moderator of the relationship conscientiousness and job performance. Journal of Applied Psychology, 85(3) 472-478.

Hogan, J., \& Holland, B. (2003). Using theory to evaluate personality and jobperformance relations: A socioanalytic perspective. Journal of Applied Psychology, 88(1), 100-112.

Hogan, R., Hogan J., \& Roberts, B. W. (1996). Personality measurement and employment decisions. American Psychologist, 51 469-477.

Holyoak, K. (1984). Analogical thinking and human intelligence. In R. J. Sternberg (Ed.) Advances in the psychology of human intelligence (Vol. 2). Hillsdale, NJ: Erlbaum.

Hough, L. (1992). The big five personality variables - construct confusion: Description versus prediction. Human Performance, 5, 139-155.

Hurtz, G. M., \& Donovan, J. J. (2000). Personality and job performance: the big five revisited. Journal of Applied Psychology, 85(6), 869-879

Jerusalem, M., \& Schwarzer, R. (1986). Selbstwirksamkeit [Self-efficacy]. In R. Scwarzer (Ed.), Skalen zur Befindlichkeit und Personlichkeit. Research Report, 5, 15-28. Berlin

Johnson-Laird, P. N. (1983). Mental Models: Towards a cognitive science of language, inference, and consciousness. Cambridge, Mass: Harvard University Press.

Judge, T. A., \& Bono, J. E. (2001). Relationship of core self-evaluations traits-selfesteem, generalized self-efficacy, locus of control, and emotional stability - With job satisfaction and job performance: A meta-analysis. Journal of Applied Psychology, 86(1), 80-92.

Judge, T. A., Erez, A., \& Bono J. E. (1998). The power of being positive: The relationship between positive self-concept and job performance. Human Performance, 11(2/3), 167-187.

Judge, T. A., \& Ilies R. (2002). Relationship of personality and performance motivation: A meta analytic review. Journal of Applied Psychology, 87(4), 797-807.

Judge, T. A., Locke, E. A., \& Durham, C. C. (1997). The dispositional causes of job satisfaction: A core-evaluations approach. Research in Organizational Behavior, 19, 151-188. 
Kenny, D. A., Korchmaros, J. D., and Bolger, N. (2003). Lower level mediation in multilevel models. Psychological Methods, 8(2), 115-128.

Klimoski, R., \& Mohammed, S. (1994). Team mental model: construct or metaphor? Journal of Management, 20(2), 403-437

Langan-Fox, J., Code, S., \& Langfield-Smith, K. (2000). Team mental models: Techniques, methods, and analytical approaches. Human Factors, 42(2), 242-271.

Langan-Fox, J., Wirth, A., Code, S., Langfield-Smith, K, \& Wirth A. (2001). Analyzing shared and team mental models. International Journal of Industrial Ergonomics, 28(2), 99-112.

Lee, C., \& Bobko, P. (1994). Self-efficacy beliefs: Comparison of five measures. Journal of Applied Psychology, 79, 33, 364-369.

Lepine, J. A. \& Van Dyne, L. (2001). Voice and cooperative behavior as contrasting forms of contextual behavior: Evidence of differential relationships with the big five personality characteristics and cognitive ability. Journal of Applied Psychology, 86, 326-336.

Locke, E. A., \& Latham, G. P. (1990). Work motivation and satisfaction: Light at the end of the tunnel. Psychological Science, 1(4), 240-246.

Lodewyk, K. R. \& Winne P. H. (2005). Relations among the structure of learning tasks, achievement, and changes in self-efficacy in secondary students. Journal of Educational Psychology, 97(1), 3-12.

Martocchio, J. J., \& Judge, T. A. (1997). Relationship between conscientiousness and learning in employee training: Mediating influences of self-deception and selfefficacy Journal of Applied Psychology, 82(55), 764-773.

Martocchio, J. J. (1992). Microcomputers as an opportunity: The influence of context in employee training. Personnel Psychology, 45, 529-552.

Matthews, G. \& Zeidner, M. (2004). Traits, states and the trilogy of the mind: An adaptive perspective on intellectual functioning.. In D. Dai \& R. J. Sternberg (Eds.) Motivation, emotion, and cognition: Integrative perspectives on intellectual functioning and development (pp. 143-174). Mahwah, NJ. Lawrence Earlbaum.

McCrae, R. R., \& Costa, P. T. (1985). Openness to experience. In R. Hogan and W. H. Jones (Eds.), Perspectives in Personality: Theory, measurement, and interpersonal dynamics (Vol. 1). Greenwich, CT: JAI Press. 
McCrae, R. R., \& Costa, P. T. (1987). Validation of the five-factor model of personality across instruments and observers. Journal of Personality and Social Psychology, 52(1) 81-90.

McDonald, J. E., Papp, K. R., \& McDonald, D. R. (1990). Hypertext perspectives: using pathfinder to build hypertext systems. In Schvaneveldt, R. W. (Ed.), Pathfinder Associative Networks: Studies in Knowledge Organization (pp. 197-211). Norwood, NJ: Ablex Publishing Corp.

Messick, S. (1984). The nature of cognitive styles: Problems and promise in educational practice. Educational Psychologist, 19(2), 59-74

Mitchell, T. R., Hopper, H., Daniels, D., George-Falvy, J., \& James, L. R. (1994). Predicting self-efficacy and performance during skill acquisition. Journal of Applied Psychology, 79(44), 506-517.

Mohammed, S., Klimoski, R., \& Rentsch, J. R. (2000). The measurement of team mental models: We have no shared schema. Organizational Research Methods, 3(2), $123-165$.

Morgeson, F. P., Campion, M. A., Dipboye, R. L., \& Hollenbeck J. R., Murphy, R., and Schmitt, N. (2007). Are we getting fooled again coming to terms with limitations in the use of personality tests for personnel selection. Personnel Psychology, 60(4), 1029-1049.

Morgeson, F. P., Delaney-Klinger, K., \& Hemingway, M. A. (2005). The importance of job autonomy, cognitive ability, and job-related skill for predicting role breadth and job performance. Journal of Applied Psychology, 90(2), 399-406.

Morine-Dershimer, G., Saunders, S., Artiles, A. J., Mostert, M. P., Tankersley, M., Trent, S. C., \& Nuttycombe, D. G. (1992). Choosing among alternatives for tracing conceptual change. Teaching \& Teacher Education, 8, 471-483.

Motowildo, S. J., \& Van Scotter, J. R. (1994). Evidence that task performance should be distinguished from contextual performance. Journal of Applied Psychology, 79, $475-480$

Mount, M. K., \& Barrick, M. R. (1995). The big five personality dimensions: Implications for research and practice in human resources... Research in Personnel and Human Resources Management, 13, 153-200

Neisser, U. (1976). Cognition and reality: Principles and implications of cognitive psychology. San Francisco: W. H. Freeman and Company. 
Ones, D. S., Dilchert, S., Viswesvaran, C., \& Judge T.A (2007). In support of personality assessment in organizational settings. Personnel Psychology, 60(4), 995-1027.

Pajares, F. (1996) Self-efficacy beliefs in academic settings. Review of Educational Research, 66(4), 543-578.

Paulhus, D. L., Bruce, M. N., \& Trapnell, P. D. (1995). Effects of self-presentation strategies on personality profiles and structures. Personality and Social Psychology Bulletin, 21, 100-108.

Pintrich, P. R., \& DeGroot, E. V. (1990). Motivational and self-regulated learning components of classroom academic performance. Journal of Educational Psychology, 82(33-40), 13-28.

Rosch, E. (1978). Principles of categorization. In E. Rosch and B. Lloyd (Eds.) Cognition and Categorization (pp. 27-48). Hillsdale, NJ: Lawrence Erlbaum Associates.

Rouse, W. B., \& Morris, N. M. (1986). On looking into the black box: Prospects and limits in the search for mental models. Psychological Bulletin, 100, 349-363.

Rowe, A. L., Cooke, N. J., Hall, E. P., \& Halgren, T. L. (1996). Toward an on-line knowledge assessment methodology: building on the relationship between knowing and doing. Journal of Experimental Psychology: Applied, 2(1) 31-47.

Rumelhart, D. E. (1984). Schemata and the cognitive system. In R. S. Wyer and T. K. Skulls (Eds.) The Handbook of Social Cognition (pp. 161-188). Lawrence Erlbaum.

Saks, A. M. (1995). Longitudinal field investigation of the moderating and mediating effects of self-efficacy on the relationship between training and newcomer adjustment. Journal of Applied Psychology, 80(22), 211-225.

Salgado, J. F. (2003). Predicting job performance using FFM and non-FMM personality measures. Journal of Occupational and Organizational Psychology, 76(3), 323346.

Schlenker, B. R. (1980). Impression Management: The self-concept, social identity, and interpersonal relations. Monterey, CA: Brooks/Cole Publishing Corp.

Schunk, D. H. (1982). Effects of effort attributional feedback on children's perceived self-efficacy and achievement. Journal of Educational Psychology, 74, 548 -556.

Schunk, D. H. (1983). Ability versus effort attributional feedback: Differential effects on self-efficacy and achievement. Journal of Educational Psychology, 75, 848 - 856. 
Schvaneveldt, R. W. (1990) Pathfinder associative networks: Studies in knowledge organization. Norwood, NJ: Ablex Publishing Corp.

Schvaneveldt, R. W. (2007). Interlink [Pathfinder 5.4]. Tucson, AZ.

Scielzo, A., Fiore S. M., Cuevas, H. M, \& Salas, E. (2002). The utility of mental model assessment in diagnosing cognitive and metacognitive processes for complex training. Proceedings of the $46^{\text {th }}$ Annual Meeting of the Human Factors and Ergonomics Society. 566-568.

Sherer, M., Maddux, J. E., \& Mercandante, S. (1982). The self-efficacy scale: Construction and validation. Psychological Reports, 51, 663-671.

Shrout, P. E. \& Bolger, N. (2002). Mediation in experimental and nonexperimental studies: New procedures and recommendations. Psychological Methods, 7(4), $422-445$

Stajkovic, A. D., \& Luthans, F. (1998). Self-efficacy and work-related performance: A meta-analysis. Psychological Bulletin, 124(2), 240-261.

Stumpf, S. A., Brief, A. P., \& Hartman, K. (1987). Self-efficacy expectations and coping with career-related events. Journal of Vocational Behaviors, 31, 91-108.

Tett, R. P., \& Christiansen N. D. (2007) Personality at a crossroads: A response to Morgeson, Campion, Dipboye, Hollenbeck, Murphy, and Schmitt. Personnel Psychology, 60(4), 967-993.

Thoms, P., Moore, K. S., \& Scott, K. S. (1996). The relationship between self-efficacy for participating in self-managed work-groups and the Big Five personality dimensions. Journal of Organizational Behavior, 17, 349-362.

Vancouver, J. B., Thompson, C. M., Tischner, E. C., \& Putka, D. J. (2002). Two studies examining the negative effect of self-efficacy on performance. Journal of Applied Psychology, 87(3) 5-06-516.

Vancouver, J. B., Thompson, C. M., \& Williams, A. A. (2001). The changing signs in the relationship among self-efficacy, personal goals, and performance. Journal of Applied Psychology, 86(4), 605-620.

Vermetten, Y. J., Lodewijks, H. G., \& Vermunt, J. D. (2001). The role of personality traits and goal orientations in strategy use. Contemporary Educational Psychology, 26(2), 149-170 
Viswesvaran, C., Ones, D. S., \& Hough, L. M. (2001). Do impression management scales in personality inventories predict managerial job performance ratings? International Journal of Selection and Assessment, 9, 277-289.

Vortec, O. U., Edwards, M. B., \& Manning, C. A. (1994). Sequences of actions for individuals and teams of air traffic controllers. Human Computer Interaction, 9,(3-4), 319-343.

Ward, J. C., \& Reingen, P. H. (1990). Sociocognitive analysis of group decision making among consumers. Journal of Consumer Research, 17(3), 245-262.

Weick, K. E., \& Bougon, M. G. (1986). Organizations as cognitive maps: Charting ways to success and failure. In H. P. Sims and D. A. Gioia (Eds.) The thinking organization: Dynamics of organization social cognition (pp. 102-135). San Francisco, CA: Jossey-Bass.

Westerman, J. W., \& Simmons, B. L. (2007). The effects of work environment on the personality-performance relationship: An exploratory study. Journal of Managerial Issues, 19(2), 288-305

Wigfield, A., \& Eccles, J. S. (1992). The development of achievement task values: A theoretical analysis. Developmental Review, 12, 265-310.

Winitzky, N. Kauchak, D., \& Kelly, M. (1994). Measuring teacher's structural knowledge. Teaching and Teacher Education, 10(2), 125-139

Wood, R., \& Bandura, A. (1989a). Impact of conceptions of ability on self-regulatory mechanisms and complex decision-making. Journal of Personality and Social Psychology, 56(3), 407-415.

Wood, R., \& Badura, A. (1989b). Social cognitive theory of organizational management. The Academy of Management Review, 14(3), 361-384.

Wood, R., Bandura, A., \& Bailey T. (1990). Mechanisms governing organizational performance in complex decision-making environments. Organizational Behavior and Human Decision Processes, 46(2), 181-201.

Zimmerman, B. J. (1995). Self-regulation involves more than metacognition: A social cognitive perspective. Educational Psychologist, 30, 217- 221.

Zimmerman, B. J., Bandura, A., \& Martinez-Pons, M. (1992). Self- motivation for academic attainment: The role of self-efficacy beliefs and personal goal setting. American Educational Research Journal, 29, 663- 676. 
Zimmerman, B. J., \& Martinez-Pons, M. (1990). Student differences in self-regulated learning: Relating grade, sex, and giftedness to self- efficacy and strategy use. Journal of Educational Psychology, 82, 51-59. 


\section{APPENDICES}

\section{Appendix A}

\section{IPIP Items}

Below are the fifty items used to measure the Big 5 traits using the

"short list" 50-item assessment. Included in the items are labeling numbers associated with the trait that each item measures along with a positive $(+)$ or negative $(-)$ scoring of that item.

Labels:

1. Extraversion

2. Agreeableness

3. Conscientiousness

4. Neuroticism

5. Openness to Experience

\section{Scoring:}

(+) Positive

(-) Negative

$\underline{\text { Items: }}$

1) $1+$ Am the life of the party.

2) 2- Feel little concern for others.

3) 3+ Am always prepared.

4) 4-Get stressed out easily.

5) 5+ Have a rich vocabulary.

6) 1- Don't talk a lot.

7) $2+$ Am interested in people.

8) 3- Leave my belongings around.

9) 4+ Am relaxed most of the time.

10) 5- Have difficulty understanding abstract ideas.

11) 1+ Feel comfortable around people.

12) 2- Insult people.

13) 3+ Pay attention to details.

14) 4- Worry about things. 
15) 5+ Have a vivid imagination.

16) 1- Keep in the background.

17) $2+$ Sympathize with others' feelings.

18) 3- Make a mess of things.

19) 4+ Seldom feel blue.

20) 5- Am not interested in abstract ideas.

21) $1+$ Start conversations.

22) 2- Am not interested in other people's problems.

23) $3+$ Get chores done right away.

24) 4- Am easily disturbed.

25) 5+ Have excellent ideas.

26) 1- Have little to say.

27) $2+$ Have a soft heart.

28) 3- Often forget to put things back in their proper place.

29) 4- Get upset easily.

30) 5- Do not have a good imagination.

31) 1+ Talk to a lot of different people at parties.

32) 2- Am not really interested in others.

33) 3+ Like order.

34) 4- Change my mood a lot.

35) 5+ Am quick to understand things.

36) 1- Don't like to draw attention to myself.

37) $2+$ Take time out for others.

38) 3- Shirk my duties.

39) 4- Have frequent mood swings.

40) 5+ Use difficult words.

41) 1+ Don't mind being the center of attention.

42) 2+ Feel others' emotions.

43) 3+ Follow a schedule.

44) 4- Get irritated easily. 
45) 5+ Spend time reflecting on things.

46) 1- Am quiet around strangers.

47) $2+$ Make people feel at ease.

48) 3+ Am exacting in my work.

49) 4- Often feel blue.

50) $5+$ Am full of ideas. 


\section{Appendix B}

\section{General Self-Efficacy Items}

Below are the ten items used to measure generalized self-efficacy. Scoring is positive for all ten items. Responses include a likert-based response set from 1 (not at all true) to 4 (exactly true).

Items:

1) I can always manage to solve difficult problems if I try hard enough.

2) If someone opposes me, I can find the means and ways to get what I want.

3) It is easy for me to stick to my aims and accomplish my goals.

4) I am confident that I could deal efficiently with unexpected events.

5) Thanks to my resourcefulness, I know how to handle unforeseen situations.

6) I can solve most problems if I invest the necessary effort.

7) I can remain calm when facing difficulties because I can rely on my coping abilities.

8) When I am confronted with a problem, I can usually find several solutions.

9) If I am in trouble, I can usually think of a solution.

10) I can usually handle whatever comes my way. 


\section{Appendix C}

\section{Histograms showing Distributions of Personality Scores}

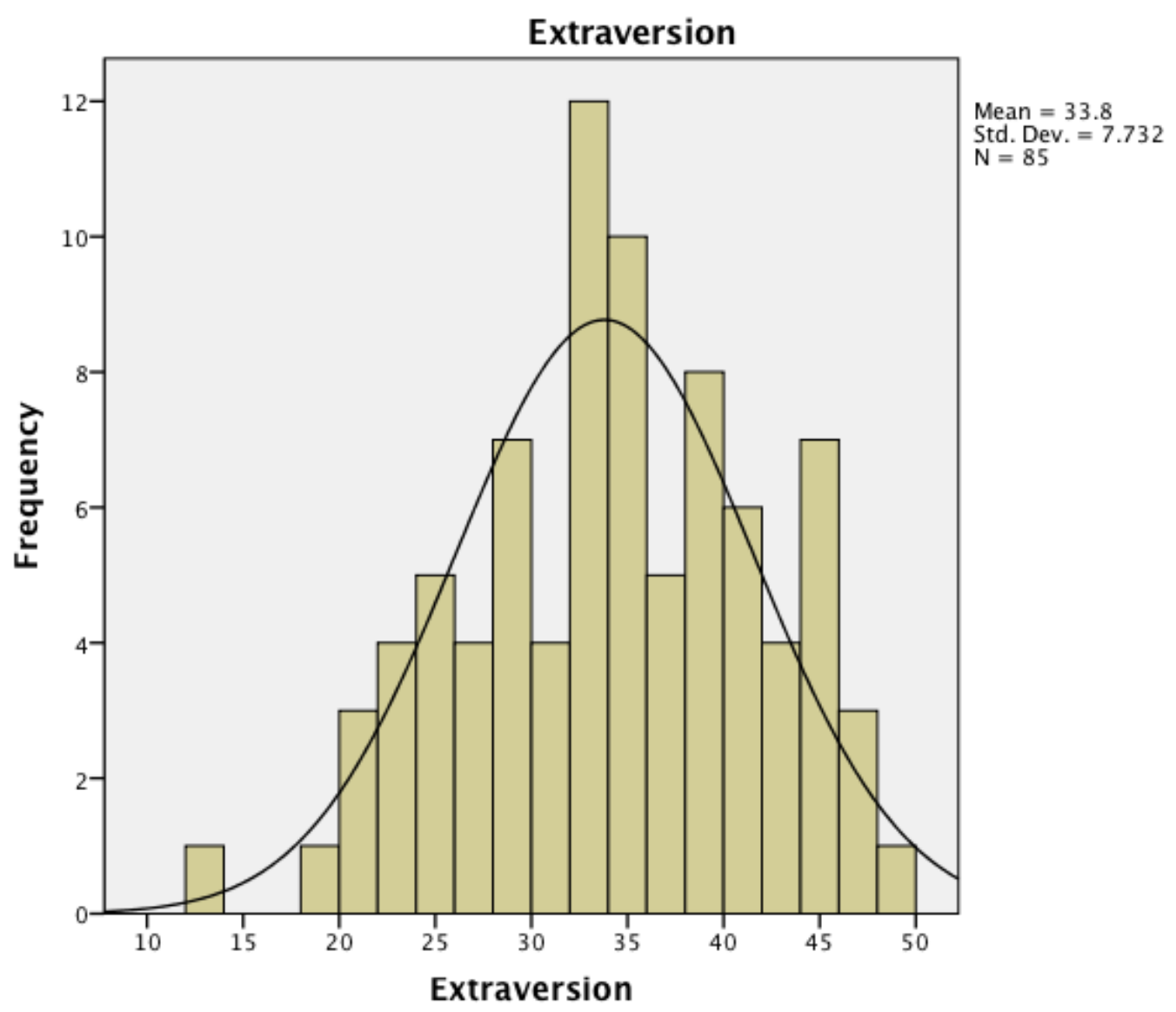




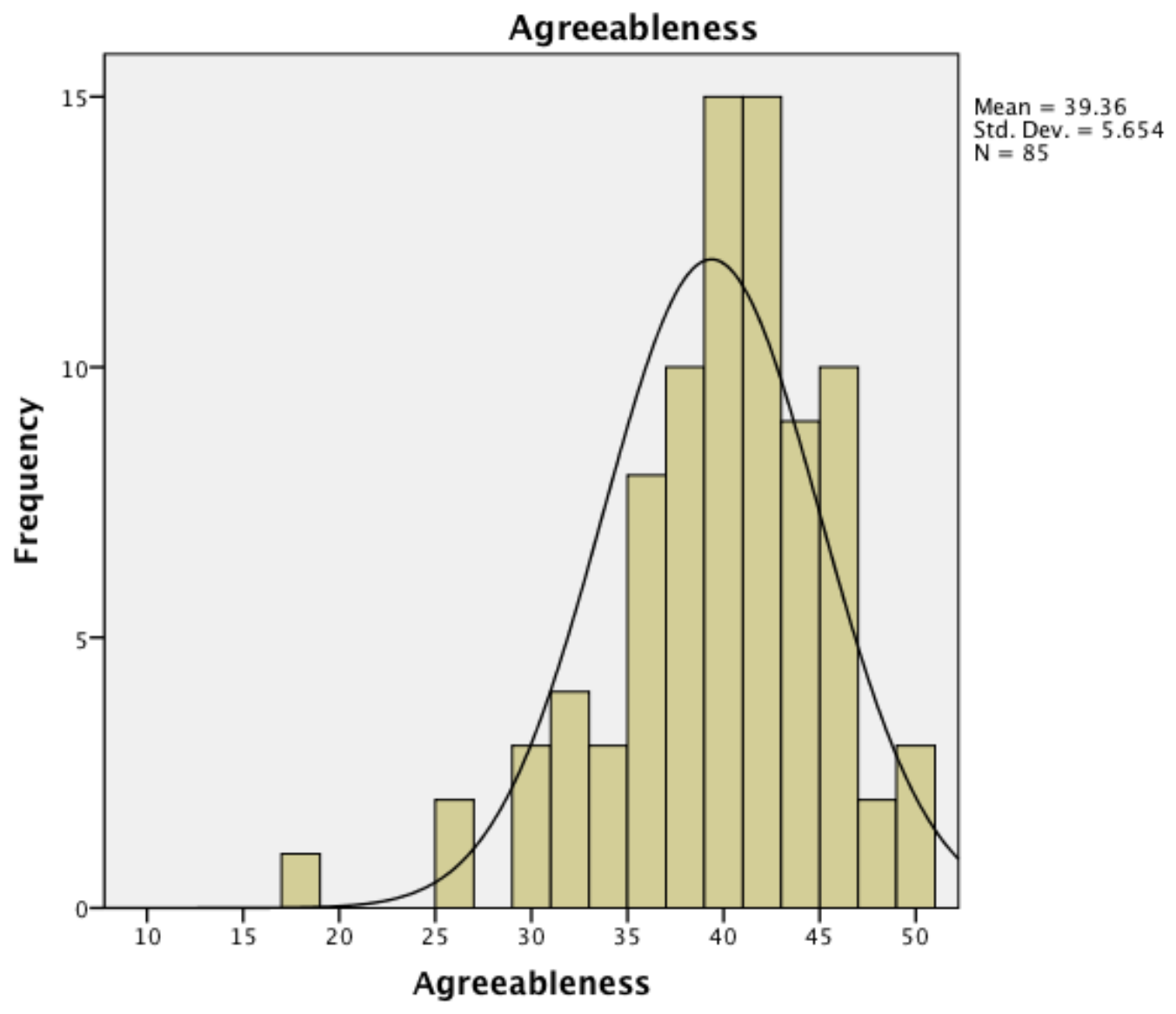




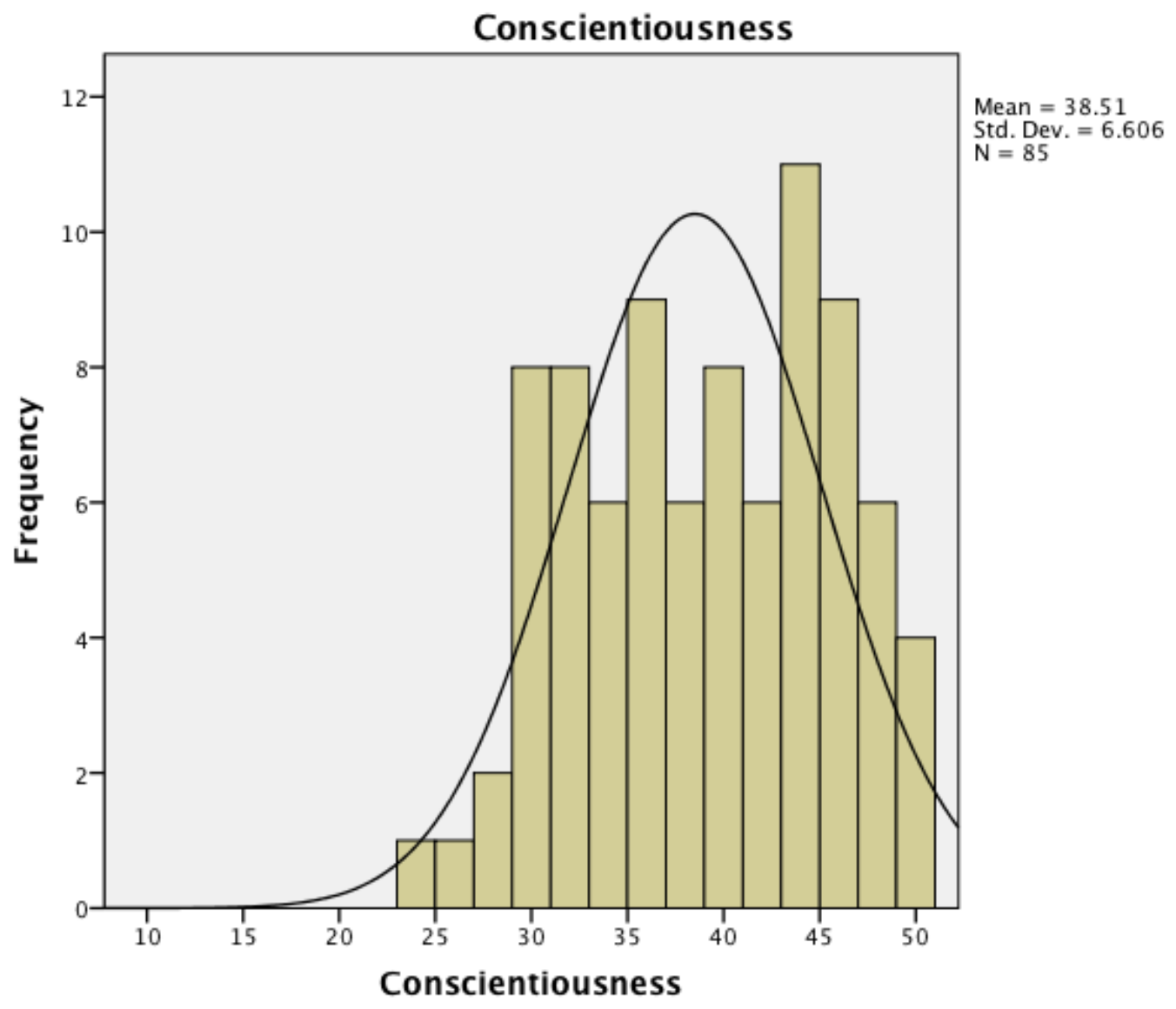




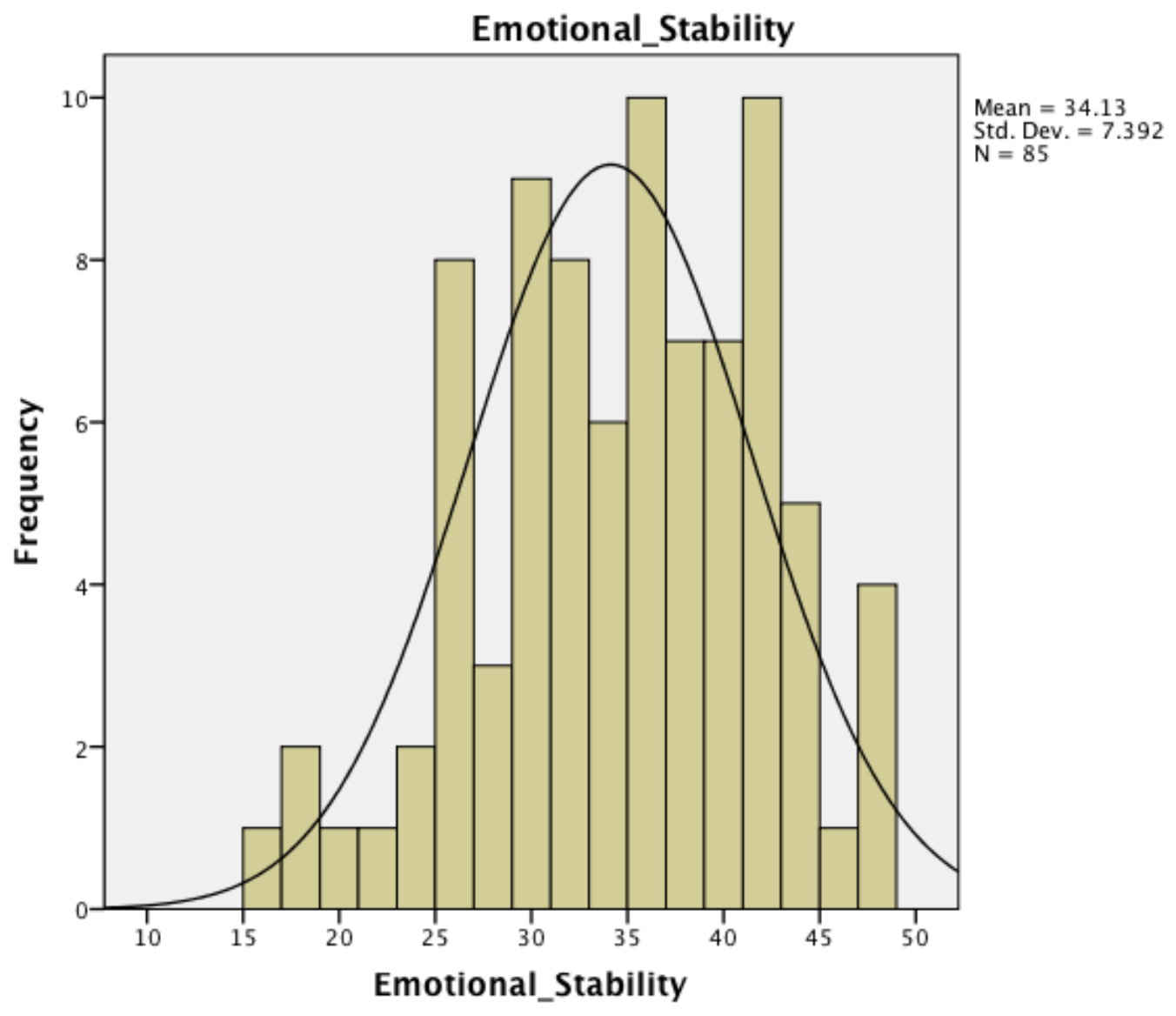




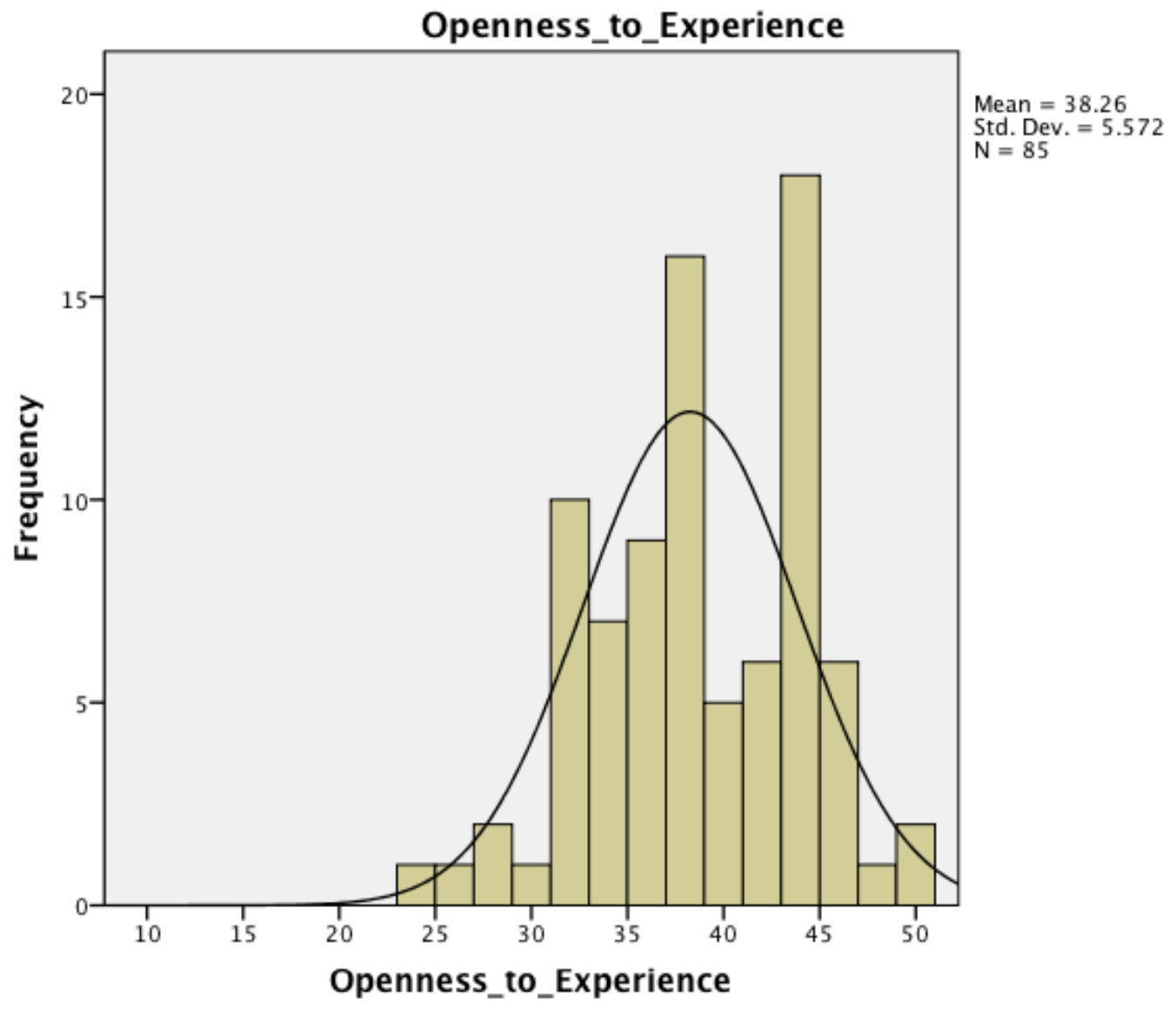




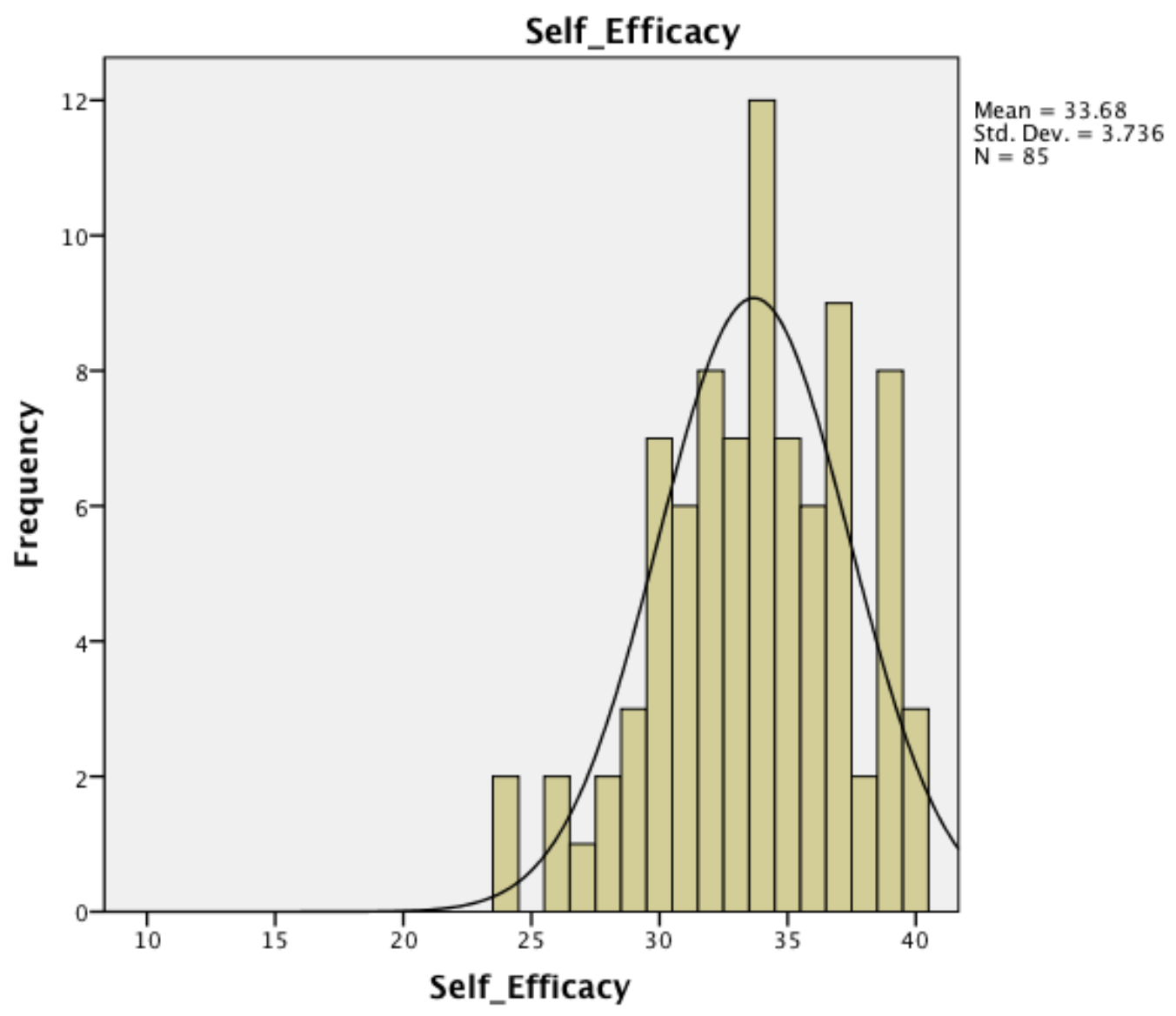




\section{Appendix D}

\section{Screenshots of Mental Model Assessments}

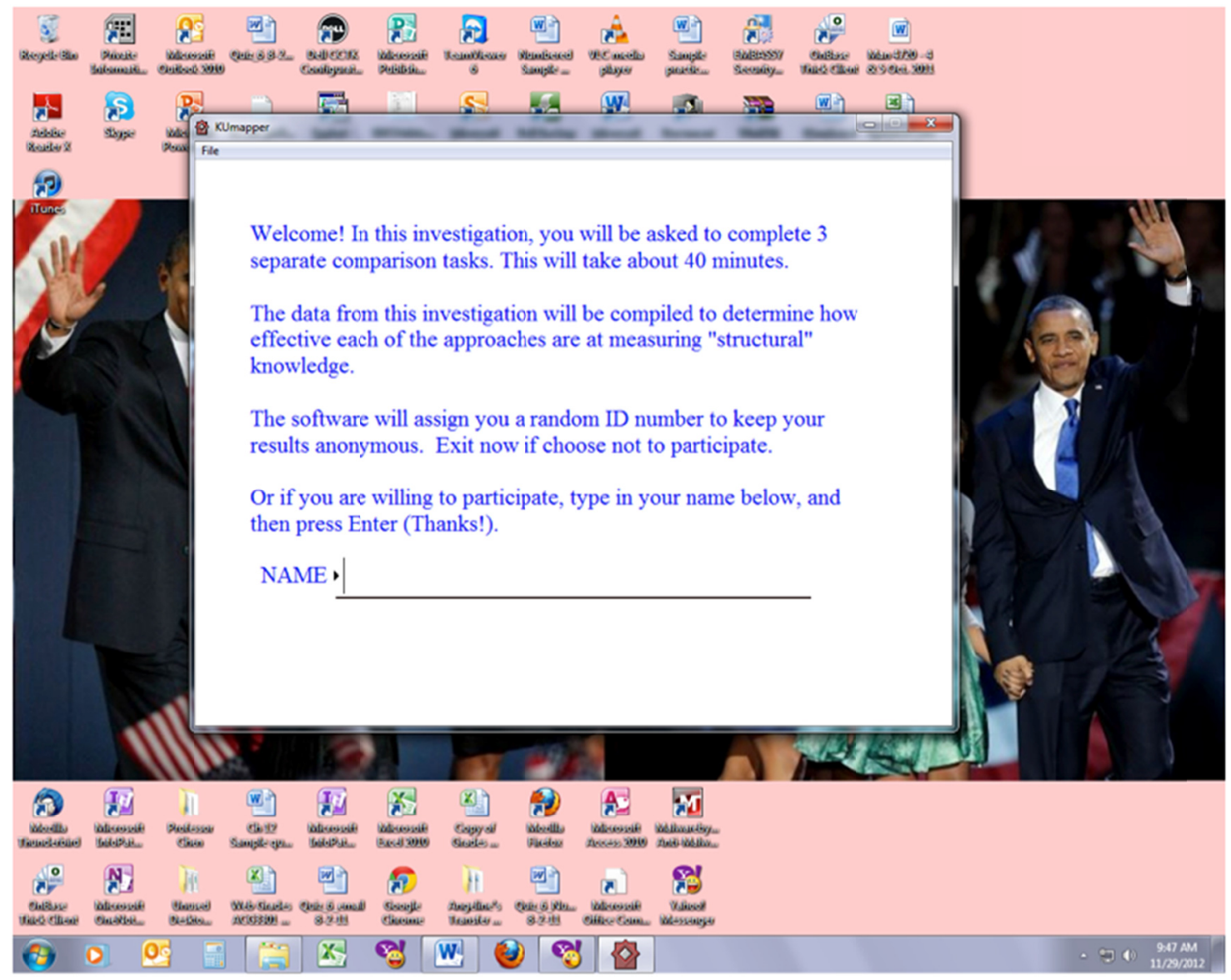

\section{Introduction Page}




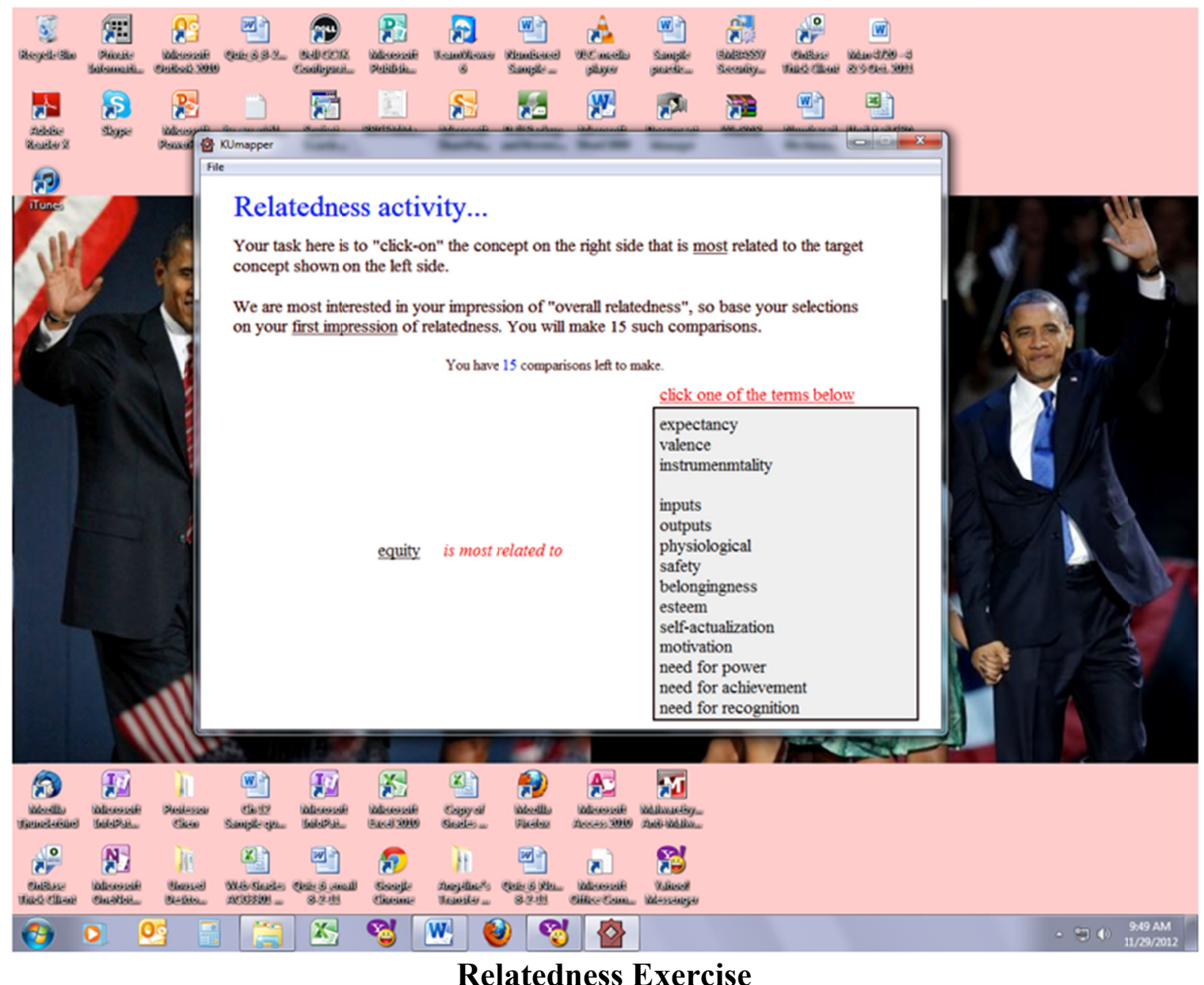

Relatedness Exercise 


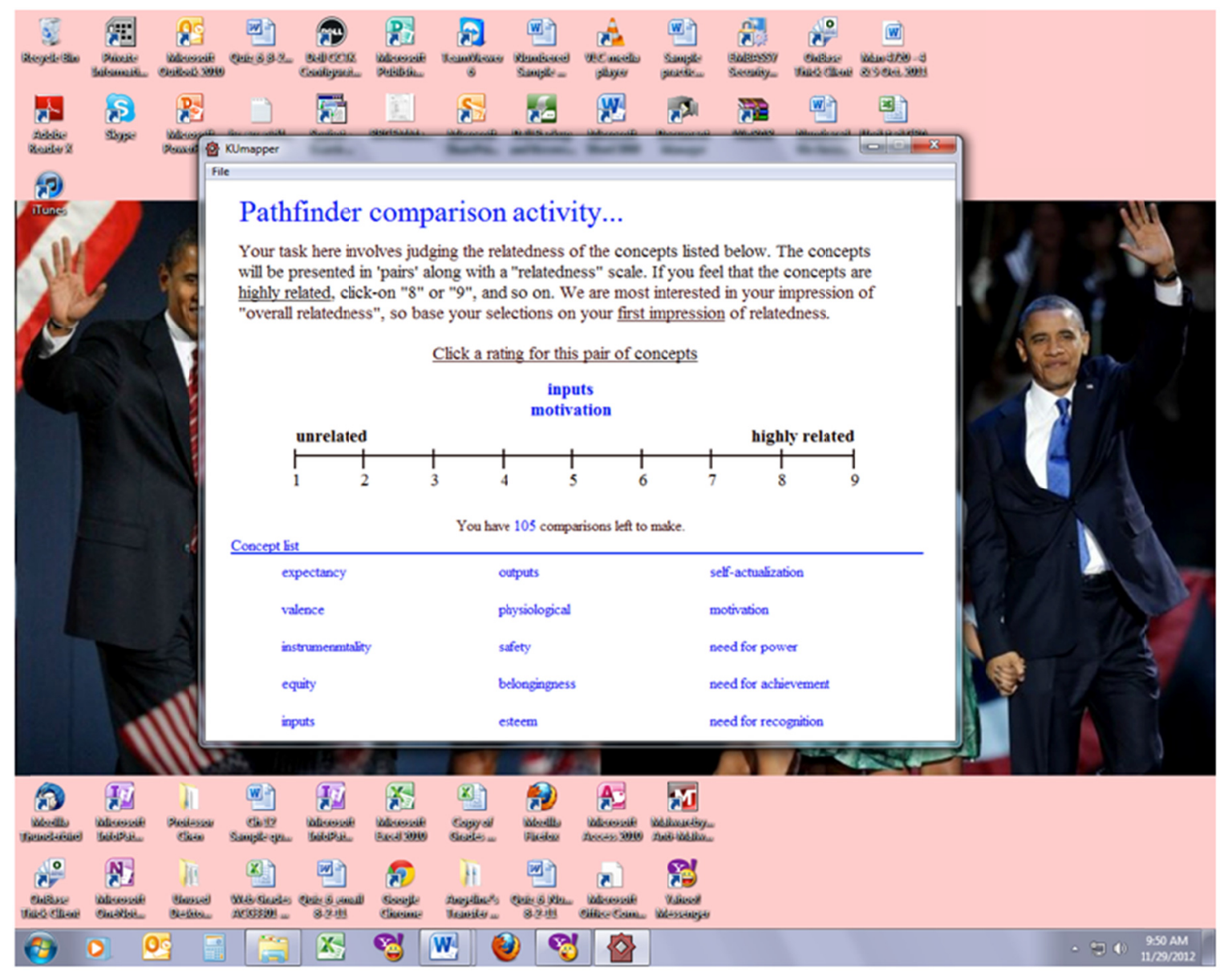

\section{Comparison Exercise}




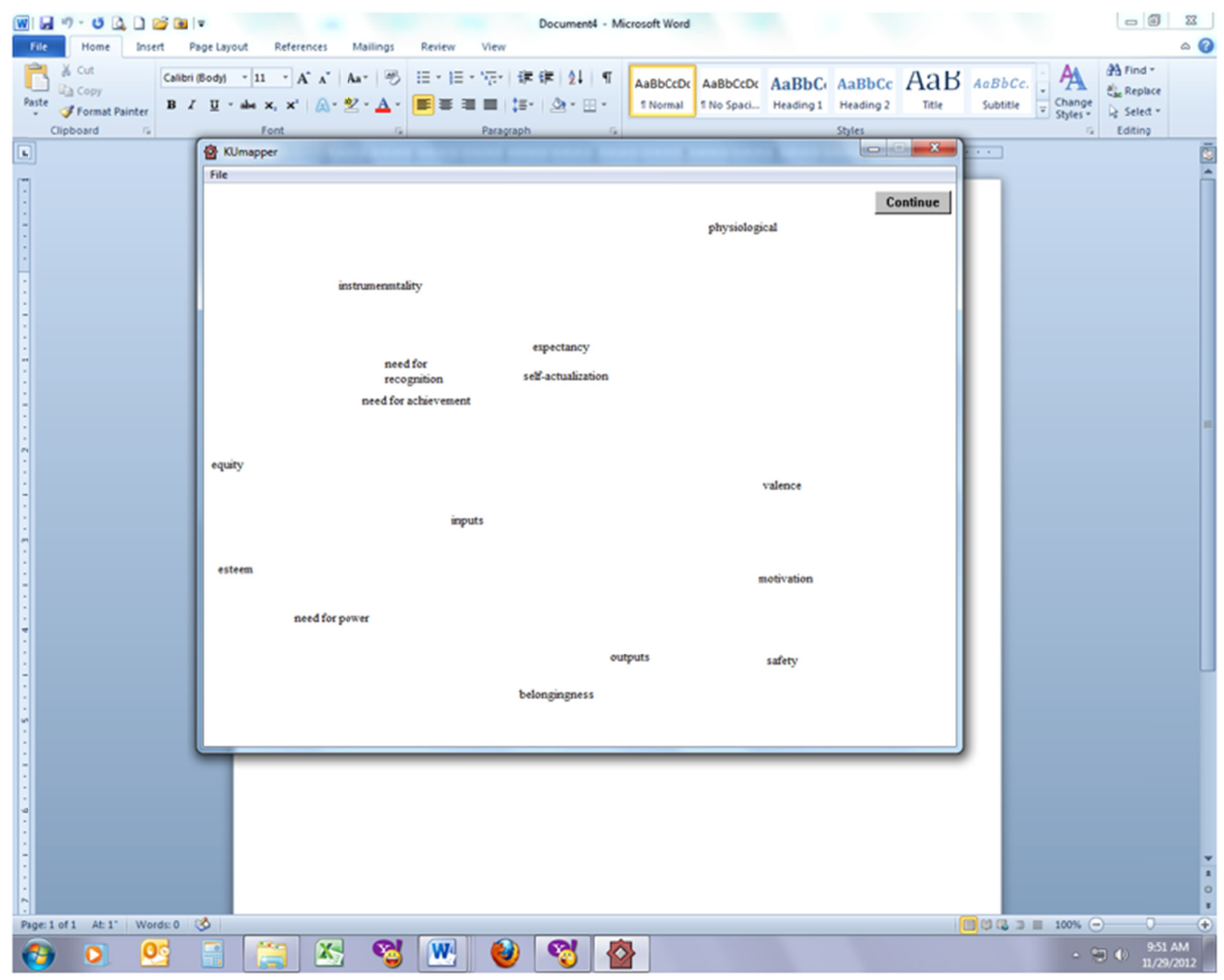

\section{Mapping Exercise}


VITA

\section{ERIC CARTAYA}

MBA, ABD, SPHR

Email: cartayae@fiu.edu

\section{EDUCATION}

Florida International University, FL

$\mathrm{PhD}$, Business

Target: Fall 2012

Dissertation Title: Personality and Performance: Assessing the mediating role of mental model formation in the personality-performance relationship

MBA, Management, May 2000

GPA: 3.5

BA, Management and Personnel Administration, December 1997

\section{PROFESSIONAL EXPERIENCE}

Florida International University

May 2007-Present*

Instructor**

Prepared curriculum and effectively taught classes at both the undergraduate and graduate level.

- Domain areas taught include:

○ Management, Human Resource Management, Organizational Behavior, Strategic Management, and Training.

- Also included, all tasks and responsibilities mentioned below as Visiting Professor.

Faculty Director

May 2007-April 2009

Masters of Science and Human Resource Management Graduate Program

- Responsible for the management, organization, and selection of incoming and current cohorts into the Master in Science in Human Resource Management program both in Miami and overseas.

Université Laval (Quebec City, Canada)

January 2007-April 2007

Charge des cours 
Prepared curriculum and effectively taught classes at both the undergraduate and graduate level.

- Created and prepared curricula tailored to Francophone and Anglophone Canadian student populations.

\section{Florida International University}

Visiting Professor

January 2005-August 2006

Prepared curriculum and effectively taught classes at both the undergraduate and graduate level including.

- Created and prepared curricula tailored to international and executive MBA programs.

$\circ$ International Executive MBA and Domestic MBA

\section{Virginia Tech}

2001-2004

Instructor (Graduate student)

Prepared curriculum and effectively taught undergraduate courses.

- Utilized all current technologies in order to increases class participation and learning

Research Assistant (Advanced Research Seminar Series)

- Developed and validated measures assessing Frame-of-Reference (FOR) Training effectiveness, rater accuracy, and Big 5 dispositional traits

Organizational Performance Dimensions, FL

1999- 2000

Consultant

Audited and consulted organizations on comprehensive human resource issues including, training, selection, workplace safety, job analysis, compensation plans, EEOC guidelines, and sexual harassment.

- Utilized Gap and Training needs analysis (TNA) to develop workshops on:

- Developed, implemented and trained top management on custom designed knowledge management frameworks and tools aimed at:

\section{RESEARCH PAPERS}

Cartaya, E. (2003). The impact of "openness to experience" and "extraversion" on the relationship between frame of reference training and rater accuracy. Currently being prepared for submission.

Personality and Performance: Assessing the mediating role of mental models in the personality-performance relationship. Dissertation in progress.

\section{PROFESSIONAL AFFILIATIONS}

Senior Professional in Human Resource Management (SHRM) 